Portland State University

PDXScholar

Summer 8-27-2013

\title{
Thinking Aloud in the Science Classroom: Can a literacy strategy increase student learning in science?
}

Lindsey Joan Mockel

Portland State University

Follow this and additional works at: https://pdxscholar.library.pdx.edu/open_access_etds

Part of the Biology Commons, Other Physical Sciences and Mathematics Commons, Science and Mathematics Education Commons, and the Secondary Education and Teaching Commons Let us know how access to this document benefits you.

\section{Recommended Citation}

Mockel, Lindsey Joan, "Thinking Aloud in the Science Classroom: Can a literacy strategy increase student learning in science?" (2013). Dissertations and Theses. Paper 1420.

https://doi.org/10.15760/etd.1419

This Thesis is brought to you for free and open access. It has been accepted for inclusion in Dissertations and Theses by an authorized administrator of PDXScholar. Please contact us if we can make this document more accessible: pdxscholar@pdx.edu. 
Thinking Aloud in the Science Classroom:

Can a literacy strategy increase student learning in science?

by

Lindsey Joan Mockel

A thesis submitted in partial fulfillment of the requirements for the degree of

Master of Science in Teaching

in

General Science

Thesis Committee:

Liza Finkel, Chair

Michael Flower

Melissa Potter

Cary Sneider

Portland State University

2013 
(C) 2013 Lindsey Joan Mockel 


\begin{abstract}
This research study investigated the effect of using the think aloud protocol while reading informational text on students' ability to learn from text in a secondary science classroom. The participants in this study were high school students $(n=47)$ in three classes of a mixed-grade Integrated Biology, Chemistry, and Physics course. The study tracked student achievement during a four-week curriculum unit on the theory of evolution and evidence for biological evolution. All students received instruction on using the think aloud protocol, and all students practiced the think aloud protocol when reading short articles related to scientific evidence for evolution. The researcher measured student's ability to read and understand science text by comparing scores from a reading skills pre-assessment and post-assessment from each student. Student surveys were conducted to gather feedback on the effectiveness of the strategy in teaching students to use a literacy strategy while reading science text. Data were analyzed using descriptive statistics.
\end{abstract}




\section{Table of Contents}

Abstract

List of Tables

List of Figures

Introduction

Literature Review

Overview of Literature Review

Literacy in Science Education

Think Aloud Protocol

Methods

Overview

Participants

Instructional Strategy

Instruments

Think Aloud Protocol surveys.

Think Aloud Protocol assessments.

Procedure

Data Analysis

Findings

Research Question 1

Student responses on assessments.

Student scores.

Research Question 2

Student scores.

Student responses on surveys.

Discussion

Research Question $1 \quad 49$

Student responses on assessments. 49

Student scores. 51

Research Question 2

Student scores. $\quad 52$

Student responses on surveys. $\quad 53$

Limitations and Recommendations $\quad 53$

References

Appendix A: Instruments

Appendix B: Student Response Samples

89

Appendix C: Research Approval Documents

111

Appendix D: An Account of a Think Aloud Protocol 


\section{List of Tables}

Table 1. Demographic profile of students at West Coast High School 14

Table 2. Program enrollments at West Coast High School 15

Table 3. Report card for West Coast High School 15

Table 4. Report of student achievement for West Coast High School 16

Table 5. Summary of demographic profile for participating classrooms 18

Table 6: Lexile® Measure for each text used in assessments 24

Table 7: Descriptive statistics for pre- and post-assessment scores 38

Table 8: Descriptive statistics for pre- and post-assessment scores 38

Table 9: Comparison of change between Period 1 and Period 4

Table 10: Comparison of change between Period 1 and Period 3

Table 11: Increase in literacy strategies reported by students 45 


\section{List of Figures}

Figure 1. Twelve thinking processes for think aloud protocol.

Figure 2. Research design.

Figure 3. Schedule of readings.

Figure 4. Strategy for answering research questions using data analysis

Figure 5. Box plot comparing pre-and post-assessment scores 


\section{Introduction}

"Language shapes science ideas and understanding" (Hand et al., 2003, pg. 608).

In 2002, the National Science Foundation hosted an international conference focused on examining current research in science education. In an editorial published from the conference, Hand et al. (2003) opined that to achieve national science education goals, researchers must study effective methods of incorporating language literacy strategies in the science classroom. The learning goals of science education that are referred to by Hand et al. (2003) include an understanding of the processes, knowledge and social practices of science (AAAS, 1989). In addition, Hand et al. (2003) argued that researchers must assess the impact of language literacy strategies on student learning in science. The study described here was designed in response to Hand et al.'s 2003 call for research examining the impact of literacy strategies on student learning in science.

The importance of this line of research may be inferred from the attention it received in 2003 when the International Journal of Science Education celebrated its $25^{\text {th }}$ anniversary. For the occasion, Dr. Larry Yore, Dr. Gay Bisanz, and Dr. Brain Hand reviewed a selection of research published over the period of 1978-2003 focused on the relationship between language literacy and science education. The authors report that research during this time period reflected a change in understanding of how people learn. Prior to this period, science education underestimated the role of language literacy in learning. Reading, writing, speaking and listening were viewed as methods of transmitting information to the learner. During the 1970s, the field of cognitive science 
developed a body of research describing human cognition and metacognition. Research revealed how humans use language to construct understanding. Using this new body of knowledge, researchers of science education began to base their research on theories of cognitive science and constructivism. This shift ultimately inspired science education researchers to explore the role of language literacy in science learning. After reviewing twenty-five years of research in science education, Yore et al. (2003) conclude that research that examines how language processes, such as reading and writing, may be used in classrooms to stimulate science learning is limited.

While science education researchers have studied the integration of literacy strategies into elementary science education, including Lee et al. (2004), there are few studies that show the effect of integrating literacy strategies on student achievement in secondary science education. In 2010, Guzzetti and Bang reviewed published studies and reported that while educational research on the efficacy of literacy-based strategies in content areas was prevalent among elementary level students, currently there is a deficit of research of this kind among secondary level students.

The purpose of this study is to investigate if a literacy strategy called the think aloud protocol can be used to improve high school students' ability to read and understand science text. The study addressed the following research questions: 1) Does using the think aloud protocol improve students' ability to read and understand science text? 2) Is a single lesson on using the think aloud protocol sufficient for students to prepare them for using the think aloud protocol when reading informational text? If not, is there any benefit to increasing the frequency of instruction on using the think aloud protocol? The hypotheses tested were: 1) Students can use the think aloud protocol to 
improve students' ability to read and understand science text. 2) Students are likely to need multiple lessons on using the think aloud protocol to demonstrate their full understanding when reading instructional text.

The study used a mixed methods design to investigate the impact of the think aloud protocol on the ability of high school students to read and understand science text during a unit of curriculum. Students were taught to use the think aloud protocol as a strategy for reading scientific text. Evidence of change in students' literacy skills was measured using student responses on reading skills pre- and post-assessments. In addition, student surveys were conducted.

Participants in this study were freshmen, sophomore, and junior level high school students enrolled in three sections of an integrated Biology, Chemistry and Physics course during the 2011-2012 school year. The class is located in an urban, public high school in the Pacific Northwest. Students received instruction on using the think aloud protocol in pairs when reading informational texts averaging 350 words. Students then independently answered short answer questions related to the science content covered in each text. During the unit of instruction, one group of students received two lessons in using the think aloud protocol, one group received a single lesson in using the literacy strategy, and one group served as the comparison group, completing the same assignments without any instruction in the think aloud protocol. This design allowed the researcher to determine whether students need multiple experiences to use the technique effectively. 
The think aloud protocol served as the intervention or the independent variable. Student ability to read and understand science text, measured by scoring student responses on pre- and post-assessments, served as the dependent variables for this study. Students initially completed a reading skills pre-assessment without the explicit use of a literacy strategy. Students were then taught to use the think aloud protocol and were asked to use the think aloud protocol when reading informational text over the course of the unit of instruction. Students then used the think aloud protocol when they completed a reading skills post-assessment. The differences in the scores of the pre-assessment and post-assessment were analyzed to determine how integrating the think aloud protocol into science instruction affected students' ability to read and understand science text. 


\section{Literature Review}

\section{Overview of Literature Review}

This literature review summarizes the role of language literacy in science education. The review begins by examining how language literacy can support student learning in science. This will include a review of research that describes the effect of integrating literacy strategies into science curriculum on student learning. The review continues by examining the think aloud protocol as a literacy strategy that supports students' ability to read and understand science text.

\section{Literacy in Science Education}

Since the 1960s, science instruction has minimized discipline-focused, language literacy and emphasized hands-on experiences in the classroom (Yore, 2003). By undervaluing the importance of language literacy, some researchers argue that science

educators may have missed an opportunity to support student learning in science (Hand et al., 2003; Norris \& Phillips, 2003; Yore, 2003). Language literacy is generally defined as the ability to comprehend information and demonstrate through writing an understanding of content knowledge (Norris \& Phillips, 2003). Not only do language literacy skills allow students to reveal their understanding of science, but "reading and writing are constitutive parts of science" (Norris \& Phillips, 2003, p. 226). Norris and Phillips (2003) argue convincingly that science educators should support students' language literacy skills to increase student learning in science. 
In order to demonstrate the effect of language literacy on student understanding, researchers studied the integration of literacy strategies in science curriculum. Researchers found evidence to suggest that literacy-based science instruction increases student achievement in both science and language literacy (Pearson et al., 2010). The findings emphasized the necessity of explicit instruction in literacy skills as students read scientific text (Pearson et al., 2010). Stemming from this body of research was a call for research to identify the most effective aspects of these literacy-based interventions on science learning.

Guzzetti and Bang (2011), Lee et al. (2004) and Fang and Wei (2010) undertook studies that demonstrate the effect of integrating language literacy in science curriculum. Guzzetti and Bang (2011) conducted a study to determine the effect of integrating literacy strategies on the interest and achievement of secondary students during a unit of chemistry curriculum. The intervention integrated literacy strategies such as fiction and non-fiction text-based reading activities, reflective writing, journaling activities, and opportunities for discussion into a unit on forensic science. Researchers found that students who experienced the intervention increased student achievement on tests that measured chemistry content knowledge and scientific inquiry skills.

Research on integrating literacy strategies in science content curriculum has also revealed a positive effect on science achievement among culturally and linguistically diverse students. Lee et al. (2004) undertook a study to measure the effect of integrating literacy strategies in science curriculum on the achievement of culturally and linguistically diverse, elementary students. The intervention integrated literacy activities 
that promoted discussion, reading and writing in science content during two science curriculum units. Researchers found statistically significant gains in achievement in both literacy skills and science content knowledge. Gains in science content knowledge were greater than gains in literacy skills.

Research also indicates that literacy strategies improve student achievement during science curriculum that includes scientific inquiry. Fang and Wei (2010) undertook a study to examine the effect of integrating language literacy strategies on the achievement of sixth grade students. The intervention integrated explicitly taught reading strategies relevant to science during a scientific inquiry unit. In addition, the experimental group participated in "home science reading program," in which they read, wrote, and discussed a science trade book in their home. Researchers found statistically significant differences between the experimental group and the control group in the areas measured. Researchers concluded that there are substantial benefits to student achievement in both scientific inquiry skills and language literacy when integrating literacy strategies in science inquiry content curriculum.

The research reported in these articles reveals that the integration of language literacy skills into science curriculum has positively impacted student learning in science. The reviewed articles report increases in student's science scores on established, standardized tests. The evidence that language literacy strategies were effective as interventions to increase student achievement in science curriculum encourages further study of this strategy. 


\section{The Think Aloud Protocol as a Tool for Literacy Skills Development}

The following studies describe the think aloud protocol in detail and describe its use as a literacy strategy. While a review of the literature did not find research describing a think aloud protocol as an intervention to improve secondary students' ability to read and understand science text, this study will use the think aloud protocol in a high school classroom of culturally and linguistically diverse students.

As a science educator, understanding how students learn science influences decision making on both curriculum design and pedagogical practices. The role of metacognition on student learning is fundamental to understanding how students incorporate new information into their established architecture of knowledge, which includes background knowledge and experience. The think aloud protocol is used in research settings a tool for measuring cognition and metacognition. Educators have also adapted it as a tool to develop literacy skills in students, especially elementary aged students. The connection between reading and metacognition is established in the literature. The think aloud protocol as a facilitator of student's learning of science is investigated in this research study.

"Reading and writing are inextricably liked to the very nature and fabric of science, and, by extension, to learning science” (Norris \& Phillips, 2003, pg. 226). In order to increase student learning in science, Yore et al. (2004) describe reading comprehension as necessary to derive meaning from scientific text and emphasize that comprehension, discussion and writing argument are language literacy skills necessary to achieve in science education curriculum. Reading comprehension is an interactive and 
constructive process. To extract meaning from a text, the reader must construct understanding using metacognitive processes. The reader is active in using literacy strategies such as connecting to prior knowledge, finding context clues, predicting vocabulary to construct meaning of science text (Yore, 2003). While the think aloud protocol was developed by cognitive science researchers to reveal and measure metacognitive processes, researchers in education have utilized a think aloud protocol to measure reading comprehension.

Researchers have used a think aloud protocol to assess elementary students' reading comprehension ability (Coté, Goldman \& Saul, 2009; Kucan \& Beck, 1996; Meyers et al., 1990). In 1990, Meyers et al. described the use of the think aloud protocol during an investigation of reading comprehension strategies with fourth and fifth grade students. Participants read aloud a passage from fictional literature sentence by sentence. After each sentence, the student reported what he or she was thinking or doing to understand the text. The researchers used probing questions to encourage responses from the student. At the end of the passage, the student summarized the text and reported any strategies they used to make meaning from the text. The researcher recorded all responses and questions. Student responses were scored based on evidence understanding, elaborating, reasoning, analyzing or judging the text. From the data gathered from the think aloud protocol, researchers categorized student cognitive behaviors when reading text. The researchers effectively used the think aloud protocol as a research tool to assess strategies used in reading comprehension. 
Reading comprehension strategies can also be taught to students using a think aloud protocol. Block and Israel (2004) outlined how to incorporate the think aloud protocol as an effective classroom literacy strategy. The authors describe the think aloud protocol as a metacognitive strategy that increases student achievement in reading comprehension. According to Block and Israel, to effectively use the think aloud protocol as a comprehension strategy, the teacher should model the following thinking processes used by expert readers.

\begin{tabular}{|l|l|l|}
\hline \multicolumn{1}{|c|}{$\begin{array}{c}\text { Before beginning or as you } \\
\text { begin reading the text. }\end{array}$} & \multicolumn{1}{|c|}{ While reading the text. } & $\begin{array}{c}\text { After reading most or } \\
\text { all of text. }\end{array}$ \\
\hline $\begin{array}{l}\text { Overview the text } \\
\text { Look for important information } \\
\text { Connect to an author's big idea } \\
\begin{array}{l}\text { Activate relevant knowledge } \\
\text { Put myself in the book }\end{array}\end{array}$ & $\begin{array}{l}\text { Revise prior knowledge and } \\
\text { predict } \\
\text { Recognize the author's writing } \\
\text { style } \\
\text { Determine word meaning } \\
\text { Ask questions }\end{array}$ & $\begin{array}{l}\text { Notice novelty in text } \\
\text { Relate the text to my life } \\
\text { Anticipate use of } \\
\text { knowledge }\end{array}$ \\
& & \\
\hline
\end{tabular}

Figure 1: Twelve thinking processes for think-aloud protocol. Block and Israel (2004)

Block and Israel (2004) explain that each of these twelve processes is appropriate before, during or after reading the text. As a strategy for encouraging students to use the think aloud protocol, the authors suggest that participants work in pairs during the protocol. As one student reads aloud and performs the think aloud protocol, the other student monitors the reader's use of the think aloud protocol. The authors support the use of the think aloud protocol as a literacy strategy because of previous studies that report the effectiveness of the think aloud protocol in increasing reading comprehension and metacognitive awareness in students. 
Baumann, Seifert-Kessell, \& Jones (1992) investigated a think aloud protocol as an intervention when elementary students read fictional text. Explicit instruction in a think aloud protocol was found to increase students' reading comprehension ability. Investigators from this study and others (Coté, Goldman \& Saul, 2009; Kucan \& Beck, 1996; Meyers et al., 1990), gathered evidence of student understanding from recording and coding participant's verbal responses. While this study supports the use of a think aloud protocol as a literacy strategy, the research reviewed suggested few instances of studying high school students' ability to read and understand informational, science text.

Science instruction must integrate literacy-based strategies into curriculum to improve students' ability to construct meaning from text. The reviewed studies emphasize the importance of language literacy in learning science. The research reveals that incorporating literacy strategies in science curriculum can increase student content knowledge and inquiry skills. The think aloud protocol has been described as a literacy strategy that reveals students' reading comprehension ability. This study will examine how the think aloud protocol affects students' ability to read and understand science text. 


\section{Method}

\section{Overview}

This study followed a mixed method, pre-post design that was designed to answer the following questions: 1) Does using the think aloud protocol improve students' ability to read and understand science text? 2) Is a single lesson on using the think aloud protocol sufficient for students to prepare them for using the think aloud protocol when reading informational text? If not, is there any benefit to increasing the frequency of instruction on using the think aloud protocol?

The study took place in a high school classroom and was conducted during a fourweek curriculum unit on evolution. During the unit the researcher also served as the student teacher. The think aloud protocol, a literacy strategy designed to help students better understand texts by activating prior knowledge and by supporting student understanding of their metacognitive processes (Tama \& Haley, 2007), was integrated into the science curriculum. Students used this protocol when reading scientific text during class assignments.

Three periods from the same high school science course were selected for the study. Students in two sections were instructed in how to use the think aloud protocol, while students in one section used the protocol with no explicit instruction. Of the two classes that received instruction, one received two lessons while the other received a single lesson. 


\begin{tabular}{l} 
Period 1: Survey $\mathrm{O}_{\text {Pre }} \mathrm{X}_{\mathrm{E}} \mathrm{O}_{\text {Post A }} \mathrm{X}_{\mathrm{E}} \mathrm{O}_{\text {Post B }}$ Survey \\
\hline Period 3: Survey $\mathrm{O}_{\text {Pre }} \mathrm{X}_{\mathrm{E}} \mathrm{O}_{\text {Post A } \mathrm{A}} \mathrm{X} \mathrm{O}_{\text {Post B }}$ Survey \\
\hline Period 4: Survey $\mathrm{O}_{\text {Pre }} \mathrm{X} \mathrm{O}_{\text {Post A }} \mathrm{X} \mathrm{O}_{\text {Post B }}$ Survey \\
$\mathrm{O}_{\text {Pre }}=$ Reading skills pre-assessment \\
$\mathrm{X}_{\mathrm{E}}=$ Think aloud protocol \\
$\mathrm{O}_{\text {Post A }}=$ Reading skills first post-assessment \\
$\mathrm{X}=$ No literacy-based strategy \\
$\mathrm{O}_{\text {Post B }}=$ Reading skills final post-assessment
\end{tabular}

Figure 2: Research design.

Student's written responses to the questions at the end of the readings were analyzed qualitatively and quantitatively to determine if using a think aloud protocol improved students' ability to read and understand science text. In order to determine if students' ability increased as a result of using the think aloud protocol, students completed a pre-assessment and two post-assessments. The assessments were modeled after reading comprehension tests used by a local school district to assess student understanding of science text. To evaluate the student responses, the researcher used the "Reading Scoring Guide for Informational Text" (ODE, 2010) to score each assessment. In addition, the study was designed to evaluate if a single lesson on using the think aloud protocol is sufficient for students to prepare them for using the think aloud protocol when reading informational text. To assess this question, student scores on the assessments as well as student responses to the final survey questions were analyzed quantitatively. In addition student responses to the final survey questions were analyzed qualitatively. 


\section{Participants}

Students at "West Coast" High School (WCHS) in the "West Coast" School District participated in this study. Students were selected to participate based on their enrollment in the integrated Biology, Chemistry \& Physics (BCP-10) course where the researcher was assigned as a student teacher. BCP-10 is a year long, required science course for all students in $10^{\text {th }}$ grade, yet enrollment rosters in the course included all high school grade levels and included students aged from 15-18 years old. In order to participate in the study, students were required to submit a signed consent form (see Appendix C), to complete the pre-assessment and both post-assessments, and to complete at least $70 \%$ of the readings (see Figure 3). Sixty-three percent of students enrolled in three sections of BCP-10 completed all of these requirements for participation $(n=47)$.

West Coast High School (WCHS) served 1,720 students in the 2010-2011 school year. WCHS has experienced an $18 \%$ decrease in the student population since the 20062007 school year. WCHS' student population is described in Table 1.

Table 1: Demographic profile of students at West Coast High School (BSD, 2011)

\begin{tabular}{|c|c|c|}
\hline Racial/Ethnic Profile of Students & School & District \\
\hline American Indian & $1 \%$ & $1 \%$ \\
\hline Asian or Pacific Islander & $7 \%$ & $13 \%$ \\
\hline Black & $3 \%$ & $3 \%$ \\
\hline Hispanic & $22 \%$ & $22 \%$ \\
\hline White & $61 \%$ & $54 \%$ \\
\hline Multiple Categories Selected & $6 \%$ & $6 \%$ \\
\hline
\end{tabular}

1 "West Coast" High School's name has been changed by the researcher to maintain confidentiality.

2"'West Coast" School District's name has been changed by the researcher to maintain confidentiality. 
The West Coast School District reported the following program enrollment at WCHS (see Table 2). This description of the student population is reflected in the presence of ESL and Special Education faculty in classrooms and in resource support rooms at WCHS.

Table 2: Program enrollments at West Coast High School (BSD, 2011)

\begin{tabular}{|l|c|c|}
\hline \multicolumn{1}{|c|}{ Program Enrollments: } & School & District \\
\hline Percent of students receiving Special Education services & $13 \%$ & $12 \%$ \\
\hline Percent of students receiving ESL services & $7 \%$ & $14 \%$ \\
\hline Percent of students receiving Free and Reduced Lunch & $37 \%$ & $38 \%$ \\
\hline $\begin{array}{l}\text { Percent of students enrolled in Talented and Gifted (TAG) } \\
\text { programs }\end{array}$ & $14 \%$ & $11 \%$ \\
\hline
\end{tabular}

The state's Department of Education labeled WCHS with an outstanding rating for the 2010-2011 school year. The ratings are based on student scores in reading, math, science and writing on standardized achievement tests. Table 3 reports the rating for WCHS over the past three school years. It reflects a yearly improvement in WCHS' rating since the 2008-2009 school year.

Table 3: Report Card for West Coast High School (ODE, 2011)

\begin{tabular}{|c|c|}
\hline \multicolumn{2}{|c|}{ State Department of Education Report Card Overall Rating: } \\
\hline $2010-2011$ & Outstanding \\
\hline $2009-2010$ & Satisfactory \\
\hline $2008-2009$ & In Need of Improvement \\
\hline
\end{tabular}

The state's Department of Education released a detailed report of student

achievement in several academic areas including reading, math, science and writing. The scores reflect achievement on state-mandated standardized tests by juniors in the 2010- 
2011 school year. The report disaggregates scores for several ethnic and racial groups. These results are detailed below in Table 4.

Table 4: Report of student achievement for WCHS (ODE, 2011)

\begin{tabular}{|c|c|c|c|}
\hline \multirow{2}{*}{$\begin{array}{c}\text { Ethnic/Racial } \\
\text { Group }\end{array}$} & \multicolumn{3}{|c|}{ Meets or Exceeds Expectations } \\
\cline { 2 - 4 } & West Coast High School & West Coast School District & State \\
\hline Asian & $72.7 \%$ & $77.3 \%$ & $71.1 \%$ \\
\hline African American & $30.0 \%$ & $42.3 \%$ & $37.7 \%$ \\
\hline Hispanic & $51.2 \%$ & $43.1 \%$ & $46.0 \%$ \\
\hline White & $87.7 \%$ & $81.0 \%$ & $76.9 \%$ \\
\hline
\end{tabular}

While the demographics of the individual participants in the study will not be described to maintain confidentiality, the demographic profile of each classroom where the study took place will be described in detail. Table 5 includes the gender, ethnic/racial, language, grade level, and classroom profile for students in Period 1, Period 3, and Period 4.

Nineteen students (76\%) in Period 1 participated in this study. 42\% of Period 1 students identify as Hispanic or Latino, and $48 \%$ percent of students identify a home language other than English. Period 1 can be characterized by a disproportionate number of males who are culturally and linguistically diverse. The females in this classroom tend to be younger in age, less likely to be linguistically or culturally diverse and more likely to be identified as Talented and Gifted (TAG) or Honors students. Period 1 was chosen to receive two lessons in using a think aloud protocol in consideration of low student achievement during the previous unit of instruction relative to the other groups in the study. 
Fifteen students (57\%) in Period 3 participated in this study. Period 3 includes 81.5\% students who identify as white and $18.5 \%$ students who identify as Hispanic or Latino. This classroom can be characterized by the high percentage of 9th graders (30\%) and the low percentage of linguistically diverse students (19\%) compared with the other classrooms in this study. Period 3 was chosen to receive one lesson in using a think aloud protocol in consideration of medium student achievement during the previous unit of instruction relative to the other groups in the study.

Thirteen students (54\%) in Period 4 participated in this study. 16\% of the students in this class are identified as linguistically diverse. This classroom can be characterized by the high percentage of $10^{\text {th }}$ graders (79\%) and the skewed gender ratio (only $33 \%$ of students are female) compared with the other classrooms in this study. Period 4 was chosen as the comparison group in consideration of high student achievement during the previous unit of instruction relative to the other groups in the study. 
Table 5: Summary of demographic profile for participating classrooms

\begin{tabular}{|c|c|c|c|}
\hline & Period 1 & Period 3 & Period 4 \\
\hline Participation Rate & $76 \%$ & $57 \%$ & $54 \%$ \\
\hline Gender (Male/Female) & $15 / 10$ & $13 / 13$ & $16 / 8$ \\
\hline Home Language & & & \\
\hline English & 13 & 21 & 20 \\
\hline Spanish & 10 & 5 & 3 \\
\hline Tagalog/Ilocano & 1 & 0 & 0 \\
\hline Chinese & 1 & 0 & 0 \\
\hline Japanese & 0 & 0 & 1 \\
\hline $\begin{array}{l}\text { Ethnicity } \\
\text { White }\end{array}$ & 11 & 21 & 15 \\
\hline Hispanic/Latino & 11 & 5 & 5 \\
\hline Asian & 2 & 0 & 3 \\
\hline African American & 1 & 0 & 1 \\
\hline ELL & $\begin{array}{l}\text { 1-Intermediate } \\
\text { 1-Advanced }\end{array}$ & 0 & 1-Intermediate \\
\hline $\begin{array}{l}\text { Grade } \\
9^{\text {th }}\end{array}$ & 5 & 8 & 3 \\
\hline $10^{\text {th }}$ & 18 & 15 & 19 \\
\hline $11^{\text {th }}$ & 1 & 3 & 2 \\
\hline $12^{\text {th }}$ & 1 & 0 & 0 \\
\hline SPED/504 & 2 & 3 & 1 \\
\hline TAG & 2 & 2 & 3 \\
\hline
\end{tabular}




\section{Instructional Strategy}

The instructional strategy used in this study is the think aloud protocol.

Participants used the think aloud protocol while reading the articles listed in Figure 3. The think aloud protocol requires students to vocalize all comments, questions, connections and thoughts aloud as he or she is challenged by a cognitive task. For the purposes of this study, the think aloud protocol was used as a literacy strategy when reading informational text related to science content.

The researcher designed the science curriculum unit to include assignments in which all students read informational text. Students in two class periods practiced the think aloud protocol when reading and responding to questions about these informational texts. A third class period read the same text and answered the same questions without being instructed in a literacy strategy.

The unit of curriculum that included these assignments was focused on biological evolution. The knowledge and skills taught during the unit were drawn from the state's Department of Education science content standards (ODE, 2009):

- H.2L.4 Explain how biological evolution is the consequence of the interactions of genetic variation, reproduction and inheritance, natural selection, and time.

H.2L.5 Explain how multiple lines of scientific evidence support biological evolution.

During the unit, classroom instruction focused on the content knowledge and skills related to H.2L.4 while the reading activities using the think aloud protocol and a handson activity designed by the researcher focused on H.2L.5. 
The evolution unit included ten days of instruction over a period of four weeks. Students completed readings during eight of the ten ninety-minute class periods. See Figure 3 for a detailed summary of the reading assignments included in the unit. During the evolution unit, every time students entered the classroom they were given a text with six questions that required short answer responses. The text was formatted specifically to include instructions for using a think aloud protocol. Students read the text using the think aloud protocol with a partner. After completing the reading, students individually answered the questions. The researcher allowed twenty minutes for students to complete the assignment.

\begin{tabular}{|l|l|l|}
\hline \multicolumn{1}{|c|}{ Date } & \multicolumn{1}{|c|}{ Article } & \multicolumn{1}{c|}{ Intervention type } \\
\hline $4 / 25 / 2012$ & "Clues in the Fossil Record" & Reading skills pre-assessment \\
\hline $5 / 9 / 2012$ & "Living Ancestors of Whales" & Practice using think aloud protocol \\
\hline $5 / 11 / 2012$ & "Darwin's Galapagos Finches" & Practice using think aloud protocol \\
\hline $5 / 15 / 2012$ & "The Origin of Feathers" & Practice using think aloud protocol \\
\hline $5 / 17 / 2012$ & "Natural Selection in Speciation" & Practice using think aloud protocol \\
\hline $5 / 23 / 2012$ & "From Water to Land" & Reading skills first post-assessment \\
\hline $5 / 29 / 2012$ & "Evolutionary History Matters" & Practice using think aloud protocol \\
\hline $5 / 31 / 2012$ & "Toxin Resistance in Snakes and Clams" & Reading skills final post-assessment \\
\hline
\end{tabular}

Figure 3: Schedule of readings

The researcher practiced a methodical approach when answering student questions during the intervention. While students practiced a think aloud protocol, they were encouraged to rely on their literacy skills to complete the reading. Although several students asked questions regarding the text, including unfamiliar vocabulary, the researcher did not answer questions directly. Instead, students were encouraged to 
interact with the text using a think aloud protocol. While students seemed frustrated at first, by the end of the intervention schedule, students questioned each other or looked to the text to find understanding.

In order to tailor the informational text to the curriculum unit on evolution, students practiced using the think aloud protocol while reading a series of articles called “15 Evolutionary Gems" published by Nature (Gee et al., 2009). The articles present evidence for evolution as case studies from the fossil record, from molecular processes and from habitats. The articles were used according to the intervention schedule described above in Figure 3.

When formatting text for student practice of the think aloud protocol, the researcher referred to the Twelve thinking processes for think-aloud protocol as described by Block and Israel (2004). The "Science Reading Work Sample" (PPS, 2011a) was used as a template when formatting the text. Modifications were made to include instructions for practicing a think aloud protocol including "determine word meanings," "activate relevant knowledge," and "look for important information" (Block and Israel, 2004).

For each of the "15 Evolutionary Gems" read by the students, the researcher wrote six short answer questions designed to check for comprehension of the text and to check for the student's ability to apply the information from the case studies to the line of evidence that supports the scientific theory of evolution. See Appendix A for each text and set of questions. The researcher scored student responses on the pre- and postassessments using the state's Department of Education's “Reading Scoring Guide for Informational Text" (ODE, 2010). Scores were analyzed to evaluate the research questions proposed by this study. 


\section{Instruments}

Described below are the pre-and post-assessments, the initial and final survey questions, and the think aloud activities students used to practice the think aloud protocol. Qualitative and quantitative data gathered from the instruments was analyzed to evaluate the research questions proposed by this study. See Appendices for each of the instruments described below.

\section{Think Aloud protocol surveys.}

Before the students completed the pre-assessment, all study participants were invited to answer a set of initial, short answer, survey questions. Students responded in written form. The initial survey asked students about any literacy strategies they employ including predicting vocabulary, connecting to prior knowledge and pausing to check for understanding. After students completed the post-assessment, all those who had completed the initial survey were asked to complete a final set of survey questions designed to elicit responses regarding the use of the think aloud protocol. Student responses on each set of questions were coded and presented as qualitative and quantitative data in the findings section of this paper. See Appendix A for the questions included in each survey. 


\section{Think Aloud Protocol assessments.}

After participants responded to the initial survey questions, all participants completed the pre-assessment. The instrument was designed in the form a "Science Reading Work Sample" (ODE, 2011a). This template was designed by the state's Department of Education as a method of assessing students' ability to understand, interpret and analyze informational text. The researcher altered the template to include elements of the think aloud protocol. This protocol requires that students reveal their understanding of text by vocalizing their questions, connections and prior knowledge as they read the text aloud.

"Clues in the Fossil Record" was the science text selected in the pre-assessment. The text was selected based on the relevance of its content to the geology unit that students completed prior to the unit on evolution. In addition, the content of the article was also relevant to the content knowledge in the unit on evolution. The text was scored using the Lexile® text analyzer. The results are reported below in Table 6.

Selected articles from the "15 Evolutionary Gems" were used as the informational text for the think aloud practice activities and the two post-assessments. Students read one of the articles daily during the curriculum unit in order to practice a think aloud protocol. See Appendix A for each instrument used by students.

After practicing using the think aloud protocol with four articles from " 15 Evolutionary Gems," students completed the first post-assessment, "From Water to Land." In accordance to the reading schedule in Figure 3 and after additional practice using the think aloud protocol, students completed the final post-assessment, "Toxin 
Resistance in Snakes and Clams." The two texts for the post-assessments were selected based on the relevance of its content to the curriculum in the evolution unit. The articles were scored using the Lexile ${ }^{\circledR}$ text analyzer. The measurements are reported in Table 6 .

Table 6: Lexile ${ }^{\circledR}$ Measure for each text used in assessments

\begin{tabular}{|l|c|c|c|}
\cline { 2 - 4 } \multicolumn{1}{c|}{} & $\begin{array}{c}\text { "Clues in the } \\
\text { Fossil Record" }\end{array}$ & $\begin{array}{c}\text { "From Water } \\
\text { to Land" }\end{array}$ & $\begin{array}{c}\text { "Toxin Resistance in } \\
\text { Snakes } \\
\text { and Clams" }\end{array}$ \\
\hline Lexile $®$ Measure & $1610 \mathrm{~L}$ & $1200 \mathrm{~L}$ & $1360 \mathrm{~L}$ \\
\hline Mean Sentence Length & 32.83 & 18.63 & 20.50 \\
\hline Mean Log Word Frequency & 3.37 & 3.35 & 3.12 \\
\hline Word Count & 394 & 447 & 287 \\
\hline
\end{tabular}

The Lexile ${ }^{\circledR}$ Framework for Reading is a tool used by educators to match a student's reading ability to an appropriate text. The Lexile ${ }^{\circledR}$ tool reports a score based on factors such as mean sentence length, mean log word frequency, and word count. Mean $\log$ word frequency describes how frequently words from the text occur on average in the Lexile ${ }^{\circledR}$ word bank. It is used to assess vocabulary difficulty in a text. Longer sentences and lower word frequency contribute to a higher Lexile ${ }^{\circledR}$ Measure, which suggests a more difficult text by comparison. The pre-assessment, first post-assessment, and final post-assessment were scored using the Lexile ${ }^{\circledR}$ Analyzer. The scores assigned by this tool will be used to compare the texts used in this study.

After reading each informational text, students responded to six questions that assessed their ability to comprehend and apply information from the text. The state's Department of Education "Scoring Guide for Information Text" was used to assess the pre-assessment and each post-assessment. Student responses on each set of questions 
were scored and presented as qualitative and quantitative data in the findings section of this paper. See Appendix A to view the scoring guide.

\section{Procedure}

To maintain confidentiality, each of the participants in the study was assigned a code by the researcher. A total of forty-seven students participated in the study (nineteen from Period 1, fifteen from Period 3, and thirteen from Period 4). All students enrolled in these class periods were expected to participate in the reading activities including the think aloud protocol. Non-participant responses to the short answer questions were isolated from participant responses. Non-participant responses were not scored and were

not used as data for this study. Participants completed a set of survey questions before the pre-assessment and after the final post-assessment. All students who qualified as participants in the study were invited to complete the survey questions. Seven students in Period 1, seven students in Period 3, and two students in Period 4 completed both sets of survey questions.

During the previous curriculum unit on geology, all students participating in the study completed the pre-assessment before they received any instruction on the think aloud protocol. The geology unit focused on state contents standards related to geologic processes and the fossil record. After the summative assessment for the geology unit, students completed the pre-assessment, "Clues in the Fossil Record" (see Appendix A). Students were instructed to sit next to a partner, read the text, and then record their answers to the content questions individually. While the text was formatted as a think 
aloud protocol, students were neither coached nor dissuaded from following the instructions while completing the pre-assessment.

Students in Period 1 and Period 3 were then taught to use a think aloud protocol when reading informational text. See Appendix $C$ for a detailed description of how the technique was modeled by the researcher. Students in Period 1 and Period 3 then practiced the think aloud protocol when reading the following articles, "Living Ancestor of Whales," "Darwin's Galapagos Finches," The Origin of Feathers," and "Natural Selection in Speciation." While students practiced the protocol, the researcher listened to each pair practice the think aloud protocol to ensure student success in use of the technique. The researcher coached students on use of the protocol when necessary. When students finished reading the text, they completed six short answer questions related to the text. Students were instructed to answer the short answer questions as individuals, not as a pair.

After Period 1 and Period 3 practiced using the think aloud protocol four times under the careful supervision of the researcher, the researcher's method of implementing the intervention changed according to the research design (see Figure 2). During the next class meeting, Period 1 received an additional lesson on how to use the think aloud protocol from the researcher. Students in Period 1 continued to receive coaching from the researcher on the use of the think aloud during the following reading activities and during the post-assessments. By contrast, Period 3 did not receive an additional lesson on the think aloud protocol. Students in Period 3 were neither coached nor dissuaded from using 
the think aloud protocol during the remaining reading assignments or during the final post-assessment.

Period 4 served as a control group for this study. Students in this class participated in the same activities and received the same materials during the curriculum unit on evolution as did the students in the other two classes. Students in Period 4 completed each of the reading activities listed in the intervention schedule (see Figure 3), but were not instructed in how to use the think aloud protocol. Students followed the procedures described above when completing the reading activities including sitting with a partner to complete the reading and responding the short answer questions. Students were not required to read the text aloud. Students received the same formatted text; they were neither coached not dissuaded from following the instructions listed on the formatted text. Participating students in Period 4 completed the pre-assessment, postassessments, and survey questions.

\section{Data Analysis}

Figure 4 summarizes how the data analysis provided evidence that addressed each research question. The data collected from the pre-assessment, first post-assessment and final post-assessment were analyzed quantitatively in order to assess if the think aloud protocol improved students' ability to read and understand science text. In addition, the quantitative data from each participant group were compared according to Figure 4 in order to determine if a single lesson on using the think aloud protocol was sufficient or if there was any benefit to increasing the frequency of instruction on using the intervention. The data collected from the student responses on the pre-assessment and final post- 
assessment was analyzed qualitatively in order to determine how the data collected from the assessments improved student understanding of science text. Finally student responses from the final survey questions were presented as qualitative and quantitative data. Responses from Period 1 and Period 4 were compared qualitatively and quantitatively to determine if a single lesson on using the intervention was sufficient.

Responses from Period 1 and Period 3 were compared qualitatively and quantitatively to determine if increasing the frequency of instruction on using the think aloud protocol was beneficial.

Figure 4: Strategy for answering research questions using data analysis

\begin{tabular}{|l|l|l|}
\hline \multicolumn{1}{|c|}{ Research Question } & \multicolumn{1}{|c|}{ Qualitative Data } & \multicolumn{1}{c|}{ Quantitative Data } \\
\hline $\begin{array}{l}\text { Does using the think aloud } \\
\text { protocol improve students' ability } \\
\text { to read and understand science } \\
\text { text? }\end{array}$ & $\begin{array}{l}\text { Comparison of selected } \\
\text { student responses from } \\
\text { the pre-assessment and } \\
\text { final post-assessment. }\end{array}$ & $\begin{array}{l}\text { Comparison of scores on } \\
\text { pre-assessment and post- } \\
\text { assessments using } \\
\text { statistical data. }\end{array}$ \\
\hline $\begin{array}{l}\text { Is a single lesson on using the } \\
\text { think aloud protocol sufficient for } \\
\text { students to prepare them for using } \\
\text { the think aloud protocol when } \\
\text { reading informational text? }\end{array}$ & $\begin{array}{l}\text { Comparison of survey } \\
\text { responses between P1 } \\
\text { and P4 }\end{array}$ & $\begin{array}{l}\text { Comparison of scores } \\
\text { between P1 and P4. } \\
\text { Comparison of reported } \\
\text { increase in frequency. }\end{array}$ \\
\hline $\begin{array}{l}\text { If not, is there any benefit to } \\
\text { increasing the frequency of } \\
\text { instruction on using the think } \\
\text { aloud protocol? }\end{array}$ & $\begin{array}{l}\text { Comparison of survey } \\
\text { responses between P1 } \\
\text { and P3 }\end{array}$ & $\begin{array}{l}\text { Comparison of scores } \\
\text { between P1 and P3. } \\
\text { Comparison of reported } \\
\text { increase in frequency. }\end{array}$ \\
\hline
\end{tabular}

A qualitative comparison of selected student responses from the pre-assessment and final post-assessment was conducted in order to determine if using the think aloud protocol improved a student's ability to read and understand science text. Student responses were categorized using the "Reading Scoring Guide for Informational Text" (ODE, 2010). The four categories defined by the rubric reflect student's understanding of the text. Student responses that characterized each category were presented in the 
findings section for comparison. By examining how the rubric evaluated student's understanding of the text, the scores from the assessments may be used to compare how the intervention affected each participant group.

Due to the samples sizes in this research study, descriptive statistics were used to analyze the data collected from student responses on written assessments. Change in mean, median and range were compared to examine the differences between groups. The pre-assessment, first post-assessment and final post-assessment completed by each of the participants were scored using the "Reading Scoring Guide for Informational Text" (ODE, 2010). The scoring guide created and validated by the state's Department of Education. The scoring guide was designed to evaluate students' ability to understand, interpret and analyze information text.

In order to establish the reliability of the ratings, the researcher scored two sets of pre-assessments three times. While there was some discrepancy between scores on the first and second round, by the third round there was very little inconsistency in the scores. To establish inter-rater reliability, six assessments from the study were scored by another science educator. The colleague was not coached on how to use the scoring guide, but the colleague was given a short description of the research design. The scores assigned by this colleague to each of the six questions on the six assessments were compared to the scores assigned by the researcher. The scores were in agreement at a rate of $69.4 \%$. The differences were also analyzed. When there was difference between scores, the colleague marked questions lower by one point by a rate of $97.2 \%$. 
Student scores on each question were recorded from the pre-assessment, first post-assessment and final post-assessment. For each student, the total score for each assessment score was calculated and recorded under a coded alias. Each group's scores were stored and calculated separately during statistical analysis in order to prevent corrupted data. The total score for each student was then used to calculate the mean for each group on each of the assessments. The mean was calculated by summing the total scores for each student in the group then dividing the sum by the number of students in the group. The median was also calculated by sorting the total score for each student in the group into ascending order then finding the number (or average of two numbers) that occurs in the middle of the set. The range of each set of scores was also calculated. From each group's set of sorted scores, a minimum score and maximum score was determined, which represents the range. In order to describe the distribution of scores around the mean, standard deviation was calculated for each assessment. Standard deviation is calculated by 1) finding the difference of each data point from the mean, 2) squaring each of these values, 3) find the average of these values, 4) taking the square root of the average. From the change in mean, median and range, the pre-assessment scores were compared to each post-assessment score between groups. The change in each of these statistical values was calculated by subtracting the mean, median or range values for two groups.

In order to determine if using the think aloud protocol improved the student's ability to read and understand science text, the statistical values, as described above, were compared. The change in mean, median, and range for Period 1 was compared to Period 4, while Period 3's change in mean, median and range was compared to Period 4. By 
comparing each group that received the intervention to the comparison group, the effect of the intervention on student ability to read and understand science text may be evaluated.

In order to determine if a single lesson on using the think aloud protocol was sufficient for students to prepare them for using the think aloud protocol when reading informational text, the statistical values, as described above, were compared. The change in mean, median and range for Period 1 was compared to Period 4. Additionally, this statistical information was used to determine if there was any benefit to increasing the frequency of instruction on using the think aloud protocol by comparing Period 1 and Period 3.

A quantitative analysis of the student responses on survey questions was conducted to address the second research question as well. Student responses that reported an increase in the frequency of using a literacy strategy included in the think aloud protocol were counted. The differences in percent increase between Period 1 and Period 4 was used to evaluate if a single lesson on using the intervention was sufficient. The differences in percent increase between Period 1 and Period 3 was used to evaluate if there is any benefit to increasing the frequency of instruction regarding the intervention.

In addition, a qualitative analysis of the student responses on survey questions was used to address the second research question. Student responses from the survey were presented in written form in order to compare the participant groups. Period 1 and Period 4 responses were compared to evaluate if a single lesson on using the intervention was sufficient. Period 1 and Period 3 responses were compared to evaluate if there was 
any benefit to increasing the frequency of instruction of the intervention. By the conclusion of the presentation of the findings, each research question was evaluated by the quantitative data and qualitative data collected during the research study. 


\section{Findings}

This research study was designed to answer two questions. The following section addresses findings for each of the research questions separately.

\section{Research Question 1}

Does using the think aloud protocol improve student's ability to read and understand science text?

In order to answer the first research question, student responses were examined quantitatively and qualitatively. Selected student responses from the pre-assessment and final post-assessment were analyzed qualitatively. Student responses from the preassessment, first post-assessment and final post-assessment were scored and compared quantitatively.

\section{Student responses on assessments.}

To evaluate if the think aloud protocol improved students' ability to read and understand science text, a selection of student responses were examined. Student responses were categorized into the following skill levels: does not yet meet, nearly meets, meets, and exceeds. These levels describe the students' ability to demonstrate understanding of the text including main ideas, supporting details, and connections among ideas. Responses from several students can been found in the results section. Selections were chosen based on similar level of understanding, as demonstrated through written response. Both questions selected from the pre-assessment and final postassessment asked students to apply information from the text as scientific evidence that supports biological evolution. Comparison of these responses demonstrates if the think 
aloud protocol improved students' ability to read and understand informational text. Copies of these student responses on the instrument can be found in Appendix B.

A selection of responses was compared in order to illustrate the various levels of understanding demonstrated by students in the pre-assessment. The following exemplify student responses from the pre-assessment that were scored as "does not yet meet." Using the scoring guide, these responses were determined to be too short, incorrect, and/or unclear. These responses suggest that the reader was unable to understand the text.

"The soft body part cast in calcium phosphate allows them to identify."

"It means that the animal that is fossilized was real."

"Because it is a 511 year fossil."

The following exemplify student responses from the pre-assessment that were scored as "nearly meets." Using the scoring guide, the responses were determined to be inaccurate or shallow. These responses suggest that the reader shows incomplete or minor understanding of main ideas.

"They prove when life form existed. They also show how the species grew over time. (in an evolutionalized way, not necessarily physically or mentally)." "Allow us to compare the modern version of an organism to its ancestors \& how it's evolved."

The following exemplify student responses from the pre-assessment that were scored as "meets." Using the scoring guide, the responses were determined to be proficient or at high school level. These responses suggest that the reader shows a correct basic understanding of main ideas and supporting details. 
"Older fossils compared to younger fossils (of the same organism) can show minute changes/differences, showing that as time goes on, evolution occurs by natural selection.”

"Fossils show how an animal looked/developed/functions, and similarities between fossils can show they are related species that evolved (changed). Examples of student responses that were scored as "exceeds" are not available from the pre-assessment. Using the scoring guide, none of the responses were determined to be insightful, complex, and/or exceed high school level. Students did not show an extremely detailed and accurate understanding of main ideas and supporting details.

A selection of responses was compared to illustrate the various levels of understanding demonstrated by students in the final post-assessment. The following exemplify student responses from the final post-assessment that were scored as "does not yet meet." Using the scoring guide, these responses were determined to be too short, incorrect, and/or unclear. These responses suggest that the reader was unable to understand the text.

"The adapt and evolve to survive."

"The adapted gene/trait is what the species prospered over the crisis."

"They eat these over time so much, they get used, to it."

The following exemplify student responses from the final post-assessment that were scored as "nearly meets." Using the scoring guide, the responses were determined to be inaccurate or shallow. These responses suggest that the reader shows incomplete or minor understanding of main ideas.

"Different varieties were present, and were weeded out, leaving the fittest ones." 
"At first these species were not resistant to the toxin, but then the evolved and became resistant to the toxin."

The following exemplify student responses from the final post-assessment that were scored as "meets." Using the scoring guide, the responses were determined to be proficient or at high school level. These responses suggest that the reader shows a correct basic understanding of main ideas and supporting details.

"The two species were pressured to change/mutate, and it eventually happened. Mutations randomly occurred, and they benefit the problems, helping populations evolve and continue to live."

"This supports the theory of evolution in that organism's molecular structures changed (evolved) to help them be more successful against predators or their environment."

Few examples of student responses that were scored as "exceeds" are available from the final post-assessment. Using the scoring guide, these responses were determined to be insightful, complex, and/or exceed high school level. Student responses show an extremely detailed and accurate understanding of main ideas and supporting details.

"Their selective pressure was a poison in their source of food and they needed to develop a resistance in order to survive. They developed a trait (well, a mutation) which served as a favorable extreme, which allowed the survival and reproduction of those who had the mutation."

The responses reviewed demonstrate the various levels of understanding demonstrated by students in Period 1 and Period 3 on the pre-assessment and final postassessment. The exemplars provided illustrate how the scoring guides' ability categorized 
students' reading comprehension. The differences in scores describe a difference in understanding. For example, a minimum score on the pre-assessment for Period 1 was a 6 , which means that the student showed "limited, confused or incorrect understanding" on each question of the pre-assessment (ODE, 2010b). The minimum score on the first post-assessment for Period 1 was a 13. This score reflects that while the student lacked understanding on every question, they did demonstrate minor understanding of the main ideas, at least. The scores were also compared quantitatively to examine if using a think aloud protocol improves students' ability to read and understand science text.

\section{Student scores.}

Student responses to six short answer questions on the pre-assessment, first postassessment and final post-assessment were scored using the Reading Scoring Guide for Informational Text (ODE, 2010b). The scoring guide categorizes student response to informational text as "does not yet meet," "nearly meets." "meets," and "exceeds." Participant responses on the pre-assessment, first post-assessment and final postassessment were scored by the researcher. The minimum possible score on each assessment was a six; the maximum possible score on each assessment was a thirty-six. Each question was scored independently. The scores for the six questions were totaled for each assessment. Descriptive statistics were calculated and used to compare each group of participants. Comparison between groups of participants was determined by examining the differences between the descriptive statistics calculated for each set of student scores. The results from these calculations are reflected in Table 7. 
Table 7: Descriptive statistics for pre-and post-assessment scores

\begin{tabular}{|c|c|c|c|}
\cline { 2 - 4 } \multicolumn{1}{c|}{} & $\begin{array}{c}\text { Period 1 } \\
\mathrm{n}=19\end{array}$ & $\begin{array}{c}\text { Period 3 } \\
\mathrm{n}=15\end{array}$ & $\begin{array}{c}\text { Period 4 } \\
\mathrm{n}=13\end{array}$ \\
\hline Pre-assessment & & & 11.1 \\
\hline Mean & 10.1 & 5.59 & 3.90 \\
\hline Standard Deviation & 3.81 & 10.0 & 11.0 \\
\hline Median & 10.0 & & \\
\hline First Post-assessment & & 16.3 & 15.5 \\
\hline Mean & 15.2 & 3.52 & 2.51 \\
\hline Standard Deviation & 2.04 & 16.5 & 15.0 \\
\hline Median & 15.0 & & \\
\hline Final Post-assessment & & 15.9 & 13.5 \\
\hline Mean & 14.5 & 5.81 & 2.60 \\
\hline Standard Deviation & 4.91 & 16.0 & 13.0 \\
\hline Median & 14.0 & & \\
\hline
\end{tabular}

Table 7 reports the mean, standard deviation and median calculated from the pre-

assessment, first post assessment and final post-assessment scores for each group of

participants. For each group, the mean and median increased from the pre-assessment to first post-assessment. By contrast, for each group the mean and median decreased from the first post-assessment to the final post-assessment. Standard deviation for each set of scores on the pre-assessment and post-assessment reveals the range of scores around the mean. In a population of students, a range of scores around a mean is expected.

Table 8: Descriptive statistics for pre- and post-assessment scores

\begin{tabular}{|c|c|c|c|}
\cline { 2 - 4 } \multicolumn{1}{c|}{} & Period 1 & Period 3 & Period 4 \\
\hline Mean Change & & & \\
\hline Pre-assessment to P1 & +5.1 & +5.2 & +3.4 \\
\hline Pre-assessment to P2 & +4.4 & +4.7 & +1.4 \\
\hline Median Change & & & \\
\hline Pre-assessment to P1 & +5.0 & +6.5 & +4.0 \\
\hline Pre-assessment to P2 & +4.0 & +6.0 & +2.0 \\
\hline Range & & & $7-20$ \\
\hline Pre-assessment & $6-19$ & $6-22$ & $12-21$ \\
\hline First Post-assessment & $13-19$ & $12-24$ & $10-19$ \\
\hline Final Post-assessment & $7-22$ & $7-27$ & \\
\hline
\end{tabular}


To compare the change in scores between the pre-assessment and each postassessment, change in mean, median and range of scores are displayed in Table 8. The mean change for each group of participants showed an increase from the pre-assessment to the first post-assessment as well as an increase from the pre-assessment to the final post-assessment. The magnitude of each increase is similar for Period 1 and Period 3 while Period 4's change in mean is less than the other groups by an average of 2.5 points. The range of scores for each group shows an increase in both the minimum and maximum scores achieved from the pre-assessment to each post-assessment. Similar to the trend for the mean and median, the greatest increase in minimum and maximum scores was between the pre-assessment and first post-assessment. Furthermore, the greatest change is in the difference of the minimum scores achieved from the preassessment to the first post-assessment. The minimum score for Period 1 increased by 7 points, by 6 points for Period 3, and by 5 points for Period 4 .

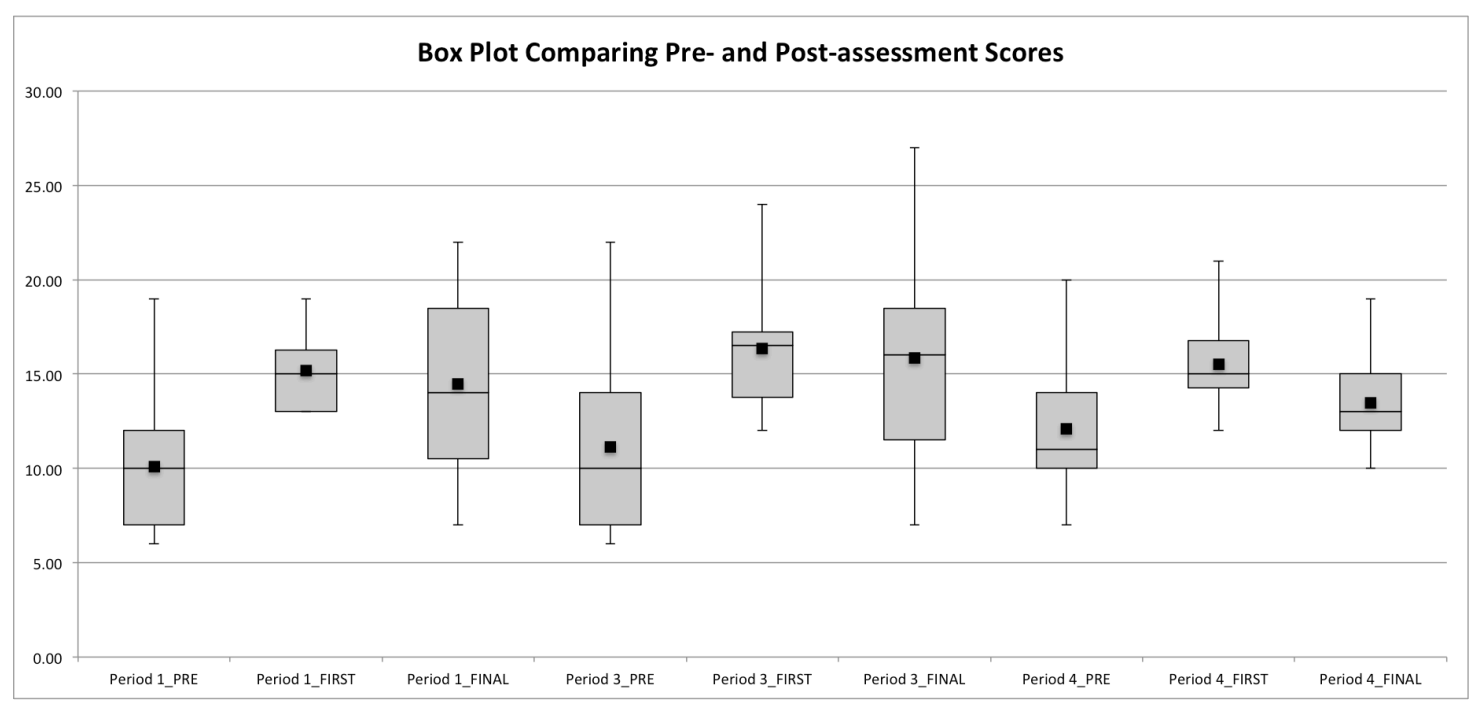

Figure 5: Box plot comparing pre-and post-assessment scores 
In order to compare the pre-and post-assessment scores for each group of participants, a box plot was constructed using descriptive statistics. Figure 5 illustrates the changes in scores between the pre-assessment, first post-assessment and final postassessment for each group. This visual representation of the statistical values makes apparent the changes in the mean, median, and range. The mean is represented by the small square inside each box, the median is represented by the line segmenting each box, and the range is represented by the whiskers extending above and below each box. The trend for Period 4, the comparison group, mirrored Period 1 and Period 3 showing a larger gain in mean and median between pre-assessment and first post-assessment than between pre-assessment and final post-assessment. For Period 1 and Period 3, preassessment scores and first post-assessment scores clustered near the minimum value for the set while the final post-assessment scores congregated nearer to the mid-range values. The range of scores for each of the assessments is generally narrower for Period 4 than for other groups. Also, the cluster of scores around the mean for each participant group was noticeably narrower for the first post-assessment than other assessments. The magnitude of each change becomes apparent as each increase is observed.

To participate in the study, students must have completed at least $70 \%$ of all activities and assessments used in this study. The completion rate of all activities and assessments is documented for each participant group. All groups had an average completion rate as follows: Period 1 (98.7\%), Period 3 (95.8\%), Period 4 (96.2\%). These completion rates ensure that participants experienced the intervention as described by the research design in this study. 


\section{Research Question 2}

Is a single lesson on using the think aloud protocol sufficient for students to prepare them for using the think aloud protocol when reading informational text? If not, is there any benefit to increasing the frequency of instruction on using the think aloud protocol?

In order to answer whether a single lesson was sufficient, responses on the preand each post-assessment from students in Period 1 and Period 4 were compared quantitatively. In addition, student responses from Period 1 and Period 4 on the final survey questions were coded and examined qualitatively and quantitatively. A selection of student responses to questions from the final survey is presented below. In order to determine if there was any benefit to increasing the frequency of instruction, responses on the pre-assessment and each post-assessment from students in Period 1 and Period 3 were compared quantitatively. In addition, student responses from Period 1 and Period 3 on the final survey questions were compared qualitatively and quantitatively.

\section{Student scores.}

Descriptive statistics calculated from the change in scores between the preassessment and post-assessments are presented in Table 7, Table 8, and Figure 5. To assess if a single lesson on using the think aloud protocol was sufficient, the differences in mean, median and range for Period 1 and Period 4 were compared quantitatively. In order to assess if there was any benefit to increasing the frequency of instruction on using the intervention, quantitative data for Period 1 and Period 3 were compared. Period 1 experienced two lessons on using a think aloud protocol when reading aloud informational text while Period 3 received only one lesson on using the technique. Period 
4 did not receive any instruction on using the think aloud protocol. Table $9 \&$ Table 10 includes descriptive statistics that address the research questions posed.

Table 9: Comparison of change between Period 1 and Period 4

\begin{tabular}{|c|c|c|}
\hline & Period 1 & Period 4 \\
\hline \multicolumn{3}{|l|}{ Mean Change } \\
\hline Pre-assessment to P1 & +5.1 & +3.4 \\
\hline Pre-assessment to P2 & +4.4 & +1.4 \\
\hline \multicolumn{3}{|l|}{ Median Change } \\
\hline Pre-assessment to P1 & +5.0 & +4.0 \\
\hline Pre-assessment to P2 & +4.0 & +2.0 \\
\hline \multicolumn{3}{|l|}{ Range Change } \\
\hline Pre-assessment & $6-19$ & $7-20$ \\
\hline First Post-assessment & $13-19$ & $12-21$ \\
\hline Final Post-assessment & $7-22$ & $10-19$ \\
\hline
\end{tabular}

The differences between scores for the pre-assessment, first post-assessment and final post-assessment from Period 1 and Period 4 are compared in Table 9. The scores for both Period 1 and Period 4 increased between the pre-assessment and first postassessment and between the pre-assessment and final post-assessment. However, the scores for both Period 1 and Period 4 did not show an increase from the first postassessment to the final post-assessment. The increase in mean and median for Period 1 was greater than each corresponding increase for Period 4. The difference in range is compared by examining the change in minimum and maximum scores. The minimum score for Period 1 had the greatest increase from the pre-assessment to the first postassessment. The maximum score for Period 1 had the greatest increase from the first post-assessment to final post-assessment. While both Period 1 and Period 4's change in mean, median and range increased from the pre-assessment to each of the postassessments, the increases for Period 1 were greater than the increases for Period 4. 
Table 10: Comparison of change between Period 1 and Period 3

\begin{tabular}{|c|c|c|}
\cline { 2 - 3 } \multicolumn{1}{c|}{} & Period 1 & Period 3 \\
\hline Mean Change & & \\
\hline Pre-assessment to P1 & +5.1 & +5.2 \\
\hline Pre-assessment to P2 & +4.4 & +4.7 \\
\hline Median Change & & +6.5 \\
\hline Pre-assessment to P1 & +5.0 & +6.0 \\
\hline Pre-assessment to P2 & +4.0 & $6-22$ \\
\hline Range Change & & $12-24$ \\
\hline Pre-assessment & $6-19$ & $7-27$ \\
\hline First Post-assessment & $13-19$ & \\
\hline Final Post-assessment & $7-22$ & \\
\hline
\end{tabular}

The differences between scores for the pre-assessment, first post-assessment and final post-assessment from Period 1 and Period 3 are compared in Table 10. The scores for both Period 1 and Period 3 increased between the pre-assessment and first postassessment and between the pre-assessment and final post-assessment. However, the scores for both Period 1 and Period 3 did not show an increase from the first postassessment to the final post-assessment. The increase in mean and median for Period 3 was greater than each corresponding increase for Period 1. The difference in range is compared by examining the changes in minimum and maximum scores. The minimum score for Period 1 had the greatest increase from the pre-assessment to the first postassessment. The maximum score for Period 3 had the greatest increase from the preassessment to final post-assessment. While both Period 1 and Period 3's change in mean, median and range increased from the pre-assessment to each of the post-assessments, the increases in all but one of these measures for Period 3 were greater than the increases for Period 1. 


\section{Student responses on surveys.}

In order to determine if a single lesson on using the think aloud protocol is sufficient for students to prepare them for using the think aloud protocol when reading informational text or if there is any benefit to increasing the frequency of instruction on using the think aloud protocol, student responses from the final survey questions are presented quantitatively and qualitatively. Period 1 received two lessons on using the think aloud protocol while Period 3 received a single lesson. Period 4 did not receive any instruction on using the think aloud protocol.

The researcher reviewed student responses from the initial survey questions to confirm the consistency of self-reporting by students. In addition, the frequency of instruction on using a think aloud protocol was varied, according the intervention schedule described in Figure 3, to assess how it may affect students' experience using a think aloud protocol. For this set of data, students were asked to self-report by answering a series of open-ended questions. See Appendix A for the list of questions used. Students reported a change in frequency of using three different literacy techniques from the pre-assessment to the final post-assessment. These techniques were pausing to check for understanding, predicting new vocabulary, and connecting text to prior knowledge. Students practiced each of these techniques during the intervention. Refer to Table 11 for the change in frequency reported by each group of participants. 


\begin{tabular}{|l|c|c|c|}
\cline { 2 - 4 } \multicolumn{1}{c|}{} & \multicolumn{1}{c|}{$\begin{array}{c}\text { Period 1 } \\
\mathrm{n}=7\end{array}$} & $\begin{array}{c}\text { Period 3 } \\
\mathrm{n}=7\end{array}$ & $\begin{array}{c}\text { Period 4 } \\
\mathrm{n}=2\end{array}$ \\
\hline $\begin{array}{l}\text { Reported increase in pausing to } \\
\text { check for understanding }\end{array}$ & $29 \%$ & $29 \%$ & $0 \%$ \\
\hline $\begin{array}{l}\text { Reported increase in predicting new } \\
\text { vocabulary }\end{array}$ & $71 \%$ & $14 \%$ & $0 \%$ \\
\hline $\begin{array}{l}\text { Reported increase in connecting text } \\
\text { to prior knowledge }\end{array}$ & $43 \%$ & $43 \%$ & $50 \%$ \\
\hline
\end{tabular}

In order to compare student responses on the final survey questions quantitatively,

student responses were coded. For each question related to the three literacy techniques used during a think aloud protocol, students reported either an increase in frequency, a decrease in frequency or no change in frequency. Coded responses that reported an increase were then converted to percentages based on the sample size of each group. Table 11 reports the increase in frequency for each literacy technique between Period 1 , Period 3 and Period 4.

Period 1 and Period 4 participant responses from the final survey showed a dissimilar increase in using these literacy techniques. Participants in Period 1 reported an increase when pausing to check for understanding and in predicting new vocabulary while participants in Period 4 reported no increase. Period 1 reported a $43 \%$ increase in connecting text to prior knowledge, and Period 4 reported a 50\% increase in using this literacy technique. Due to the small sample size of Period 4, this percentage translates that one student in Period 4 reported an increase while three students reported an increase from Period 1.

Period 1 and Period 3 participant responses from the final survey showed a similar increase in frequency when pausing to check for understanding and connecting 
text to prior knowledge. Participants in Period 1 reported a greater increase in predicting new vocabulary than participants in Period 3. Overall, the change in frequency for these three literacy techniques, as reported by student responses, was less than a $50 \%$ increase. The one exception is Period 1's reported increase in predicting new vocabulary, which shows a $71 \%$ increase in frequency.

To compare how each group of students reported a change in frequency of using literacy technique used during the think aloud protocol, the average reported increase in frequency was calculated. The average increase in frequency for using a literacy technique was greatest for Period 1 (0.48), while Period 3 reported an average increase of 0.29 , and the control group reported an average increase of 0.16 .

Selected student responses from each participant group are presented below for qualitative comparison. One of the final survey questions asked students to report how their understanding of how to read text changed after a teacher demonstrated a technique like the think aloud protocol. The following selection of responses to this question was chosen from each group of participants. Responses were chosen based on the students' overall report of change in frequency for the literacy techniques surveyed.

The following two selections were taken from students in Period 1. The first response was taken from a student who reported no change in any of the techniques; the second response was taken from a student who reported a change in two of the three techniques surveyed.

"It reminds me that I need to do more critical thinking and understanding sentences."

"It helps you think better and harder. It also helps you get an image in your head." 
Similarly, the following two selections were taken from Period 3. In addition, a third student response was taken from a student who reported a decrease in frequency for one of the literacy techniques and no change in the remaining two techniques.

"It makes you understand of different things you can do to understand your reading."

"It improves it. I do it much more than I used to, so it's helped."

"I'm visual and hands on learner. Saying it aloud only jumbles the information, I tend to make more connections in my head than out loud."

Finally, the following two selections were taken from the comparison group, Period 4. The first student reported no change in any of the literacy techniques, while the second student reported an increase in one of the three and no change in the remaining two.

"It makes it so I understand better."

"It makes me think about all the possibilities the info may relate too."

Each of the selected responses from the final survey question reported an improvement in understanding of the text when using a literacy technique like the think aloud protocol. The only exception was from one student from Period 3 who reported that the reading and thinking aloud does not support their learning style. Students reported that their increased understanding of the text was a result of examining the text critically in order to find connections. There was no categorical difference between the positive responses from each of the participant groups apart.

The findings reported provide evidence used to answer the two research questions proposed by this study. In order to determine if students' ability to read and understand 
science text was improved by using the think aloud protocol, quantitative and qualitative data was analyzed. Student scores from the pre-assessment and post-assessments were compared between participant groups. In addition, these scores were used to compare the difference in change between Period 1 and Period 4 and between Period 1 and Period 3. These comparisons were used to consider if a single lesson was sufficient or if there was any benefit to increasing the frequency of instruction on using the intervention. A selection of student responses from the pre-assessment and post-assessments were also compared to answer the second research question. In addition, student responses from the final survey were analyzed using qualitative and quantitative measures. Student responses were coded and compared quantitatively based on reported change in using literacy strategies when reading text. Each research question was evaluated using evidence presented in the findings in the discussion section. 


\section{Discussion}

This study was designed to answer two research questions. The following section addresses each of the research questions separately.

\section{Research Question 1}

Does using the think aloud protocol improve students' ability to read and understand science text?

\section{Student responses on assessments.}

In order to investigate if using a think aloud protocol improves students' ability to read and understand science text student responses on assessments were compared qualitatively. Student responses illustrated various levels of understanding. The student responses included in this study were taken from Period 1 and Period 3. The responses exemplify students' ability to apply information from the text as scientific evidence that supports biological evolution. By comparing the selected student responses from each category, this qualitative data were used to evaluate the first research question.

Selected pre-assessment responses showed limited or incorrect understanding of the text. Each response failed to answer the question by applying information from the text. Students suggested that fossils provide evidence of past life, or that fossils show that life changed over time. The text offers information including 1) paleontologists use early arthropod fossils to illustrate change in arthropod phylum over time, 2) this early arthropod fossil provides evidence for a slower rate of evolution than previously hypothesized by the Cambrian explosion, 3) this fossil provides an evolutionary step between early Cambrian arthropod to modern crustaceans, 4) new evidence collected by scientists refines our understanding of the history of evolution. While students suggest 
generally that fossils provide evidence for the history of evolution, no one successfully applied information from the text in their explanation.

Selected responses from the first post-assessment showed minor understanding of the main ideas. Four responses failed to answer the question by applying information from the text while four responses successfully applied information from the text in their answers. Students suggested that genetic variation led to favorable traits, which allowed the species to adapt and survive. The text offers information including 1) scientists studying two different taxa found a similar adaptation, 2) this adaptation occurred as a single mutation in a gene which provides toxin resistance, 3) this adaptation resulted from a selective pressure in the environment, 4) the occurrence of this evolutionary change in disparate taxa supports the scientific theory of evolution. Several students were able to apply information from the text to describe the adaptation as a genetic mutation that resulted from a selective pressure in the environment.

By comparing student responses from the pre-assessment and final postassessment, a difference in student comprehension of the text can be inferred. Before students were trained in using the think aloud protocol, their responses demonstrated limited understanding of the text. After students had been trained in using the think aloud protocol, student responses showed greater understanding of the text. Student understanding of the text can be inferred by how they applied information from the text in their responses to questions. Therefore these findings provide evidence that the think aloud protocol improved students' ability to read and understand science text. 


\section{Student scores.}

In addition to the student responses presented, a comparison of scores on assessments provided evidence that the intervention improved students' ability to read and understand science text. All participant groups showed an increase in mean and median between the pre-assessment and each post-assessment. By comparing the change in Period 1 and Period 3 scores to the comparison group, an improvement in student ability to read and understand informational text can be correlated to using the think aloud protocol.

When considering the improvement in ability to read and understand science text the profile of each participant group should be considered. Students in Period 1 were the most linguistically and ethnically diverse participant group that included two English Language Learners. In addition, Period 1 was chosen to receive two lessons in using a think aloud protocol in consideration of low student achievement during the previous unit of instruction relative to the other groups in the study. Period 3 students were characterized by a linguistic and ethnic diversity that was more similar to the comparison group, Period 4. Period 3 was chosen to receive one lesson in using a think aloud protocol in consideration of medium student achievement during the previous unit of instruction relative to the other groups in the study. By comparison, Period 4 was chosen as the comparison group in consideration of high student achievement during previous units of instruction. Therefore, the change in scores for Period 1 and Period 3, as compared to Period 4, suggest that by integrating the think aloud protocol in science curriculum, STEM educators can improve a linguistically, ethnically and academically diverse population of students' ability to understand science text. 


\section{Research Question 2}

Is a single lesson on using the think aloud protocol sufficient for students to prepare them for using the think aloud protocol when reading informational text? If not, is there any benefit to increasing the frequency of instruction on using the think aloud protocol?

\section{Student scores.}

In order to determine if a single lesson on using the think aloud protocol is sufficient for students to prepare them for using the technique when reading informational text, student scores from Period 1 and Period 4 were compared. Period 1 experienced a single lesson on using the technique while Period 4 did not experience the intervention. While both experienced an increase in ability to read and understand science text, the change in mean, median and range for Period 1 and Period 4 are different. Period 1 experienced a greater change in all three measures as described in Table 9. These findings suggest a single lesson on using the think aloud protocol is sufficient. In order to assess if there was any benefit to increasing the frequency of instruction on using the intervention, student scores for Period 1 and Period 3 were compared. Period 1 experienced two lessons on using a think aloud protocol while Period 3 received only one lesson on using the technique. Period 3 experienced a greater change in all three measures as described in Table 10. These findings suggest that there is no benefit to increasing frequency of instruction on using the think aloud protocol. 


\section{Student responses on surveys.}

The student responses to survey questions demonstrate the difference in students' experience using a think aloud protocol when reading science text. Students in Period 1 reported an increase in predicting new vocabulary that was greater than Period 3. Otherwise, there was no difference between students' selfreported change in frequency. The average increase in frequency for using a literacy strategy was greatest for Period 1. The comparison of Period 1 and Period 3 suggests that there is some benefit to increasing the frequency of instruction of the intervention. The selection of responses revealed that students self-reported an increase in understanding when using the technique. The dissimilar increase in using the literacy techniques between Period 1 to Period 4 suggest that a single lesson on using the think aloud protocol is sufficient.

To conclude, the think aloud protocol does improve students' ability to read and understand text. The improvement was observed across a diverse population of students. A single lesson on using the think aloud protocol is sufficient to prepare students for using the technique effectively. While quantitative findings suggest that there is no benefit to increasing the frequency of instruction on using a think aloud protocol, qualitative data reveals that students that experience two lessons in using the technique reported a greater increase in employing a literacy technique when reading science text.

\section{Limitations.}

In order to consider the implications of this study on teaching and learning in the science classroom, several limitations must be considered. The Lexile ${ }^{\circledR}$ Measure was 
used to compare the difficulty of the text used in each assessment. The pre-assessment, "Clues in the Fossil Record," was determined by the tool to be the most difficult text compared to the first post-assessment text and final post-assessment. In addition, "Toxin Resistance in Snakes and Clams," the final post-assessment, was determined by the Lexile ${ }^{\circledR}$ Measure to be more difficult than "From Water to Land," the first postassessment. This difference in difficulty as determined by the Lexile ${ }^{\circledR}$ Measure should be considered when analyzing data in this study. A difference in student ability may be correlated to a difference in the difficulty of the text. The Lexile ${ }^{\circledR}$ Measure is used for this reason to match an appropriate text to students' reading comprehension level. The differences between participant groups in this study are meaningful because the study used a comparison group when presenting the findings. Therefore any difference in score due to the difficulty of text is eliminated when comparing each experimental group to the comparison group. Therefore a difference in Lexile ${ }^{\circledR}$ Measure, while important to consider, does not negate the changes observed in the quantitative and qualitative data collected. A further study that eliminates a difference in Lexile ${ }^{\circledR}$ Measure when comparing the impact of the think aloud protocol on students' ability to read and understand text is needed.

Furthermore, student understanding of the science text was determined by scoring written student responses. A think aloud protocol has been shown in other studies to support reading comprehension when understanding is demonstrated by participant's verbal responses. There has not been another study that relies on students' written responses to reveal the effect of a think aloud protocol on students' ability to read and 
understand text. This question awaits research that evaluates the reliability of measuring student understanding through student written response.

\section{Recommendations.}

Integrating literacy strategies into curriculum has been shown to increase students' ability to read and write in the content area. Researchers have measured student understanding by analyzing students' ability to read and write in the content area. This study integrated the think aloud protocol into a unit of curriculum as a literacy strategy for reading science text. The findings provided evidence that the intervention improved students' ability to read and understand text. This study contributed to the body of research that suggests integrating literacy strategies increases students' understanding of science content.

While other studies investigated how a literacy strategy improved student achievement in other content areas and among young students, this study offered evidence that the think aloud protocol improves high school students' ability to read and understand science text. While this conclusion suggests that student learning in science may be improved through the integration of literacy strategies in science curriculum, this study was not designed to measure students' science content knowledge. Therefore, future studies should investigate how science content knowledge may be increased using a literacy strategy such as the think aloud protocol.

This study provided evidence that a think aloud protocol improved students' ability to read and understand science text. In addition, the study suggests that a single lesson in using the think aloud protocol is sufficient to prepare students to use the literacy strategy. Therefore, the think aloud protocol is a literacy strategy that requires less than 
twenty minutes to prepare students to use. In order to improve understanding of science text, STEM educators should instruct students in using a literacy strategy such as the think aloud protocol.

Training students in how to use a literacy technique was effective yet simple. After the initial training and coaching, students methodically practiced the think aloud protocol when asked to read a text. The protocol requires focus and participation by every student. This resulted in a quietly murmuring classroom of focused students. Once students moved onto answering the questions, conversations between students remained focused. Students were intently referring to the text to find answers to the questions. Listening to students critically analyzing text was a rewarding experience as a science educator. By comparison, the group that did not receive the intervention was also quietly focused, but there was no conversation between students concerning the text. Informal observations of students practicing the think aloud protocol rewarded the effort of designing the study. 


\section{References}

American Association for the Advancement of Science. (1989). Science for all American. Washington DC: Oxford University Press. Retrieved from http://www.project2061.org/publications/sfaa/online/sfaatoc.htm

Baumann, J.F., Seifert-Kessell, N. \& Jones, L.A. (1992). Effect of Think-Aloud Instruction on Elementary Students' Comprehension Monitoring Abilities. Journal of Literacy Research, 24, 143-172.

Beaverton School District. (2011). Historical and current indicators from State Reports and the BSD Annual Survey. Retrieved from http://www.beaverton.k12.or.us/pdf/dist/res_rep/dist_res_rep_bsd_statistics.pdf

Block, C.C. \& Israel, S.E. (2004). The ABCs of Performing Highly Effective ThinkAlouds. The Reading Teacher, 58(2), 154-167.

Coté, N., Goldman, S.R. \& Saul, E.U. (2009). Students making sense of informational text: Relations between processing and representation. Discourse Processes, $25(1), 1-53$.

Fang, Z., \& Wei, Y. (2010). Improving Middle School Students' Science Literacy through Reading Infusion. Journal of Educational Research, 103(4), 262-273.

Gee, H., Howlett, R. \& Campbell, P. (2009). 15 Evolutionary Gems. Nature, 457(8). Retrieved from http://www.nature.com/nature/newspdf/evolutiongems.pdf

Guzzetti, B. J., \& Bang, E. (2011). The Influence of Literacy-Based Science Instruction on Adolescents' Interest, Participation, and Achievement in Science. Literacy Research and Instruction, 50(1), 44-67. 
Hand, B.M., Alvermann, D.E., Gee, J., Guzzetti, B.J., Norris, S.P., Phillips, L.M., Prain, V., Yore, L.D. (2003). Message from the "Island Group": What Is Literacy in Science Literacy? Journal of Research in Science Teaching, 40(7), 607-615.

Kucan, L. \& Beck, I.L. (1996). Four Fourth Graders Thinking Aloud: An Investigation of Genre Effects. Journal of Literacy Research, 28(2), 259-287.

Lee, O., Deaktor, R. A., Hart, J. E., Cuevas, P., Enders, C. (2005). An Instructional Intervention's Impact on the Science and Literacy Achievement of Culturally and Linguistically Diverse Elementary Students. Journal of Research in Science Teaching, 42(8), 857-887.

MetaMetrics (2013). Using the Professional Lexile Analyzer®. Retrieved from https://www.lexile.com/tools/lexile-analyzer/using-the-professional-analyzer/ Meyers, J., Lytle, S., Palladino, D., Devenpeck, \& Green, M. (1990). Think-Aloud Protocol Analysis: An Investigation of Reading Comprehension Strategies in Fourth- and Fifth-Grade Students. Journal of Psychoeducational Assessment, 8, 112-127.

National Research Council. (1996). National science education standards. Washington, DC: National Academy Press.

Norris, S.P., \& Phillips, L.M. (2003). How Literacy in Its Fundamental Sense Is Central to Scientific Literacy. Science Education, 87(2), 224-240.

Oregon Department of Education. (2011). Oregon Statewide Report Card 2010-2011. Retrieved from http://www.ode.state.or.us/data/schoolanddistrict/testresults/reporting/pagrsurpres sed.asp 
Oregon Department of Education (2010a). Practice Work Sample \#2: The Science of Disappearing. Adapted from Ornes, S. (2008, February 17). The Science of Disappearing [Article]. Retrieved from http://www.pps.k12.or.us/files/curriculum/The_Science_of_Disappearing_Work_ Sample.pdf

Oregon Department of Education (2010b). Student-Language Reading Scoring Guide for Informational Text. Retrieved from http://www.pps.k12.or.us/files/curriculum/Student_Scoring_Guide_Info.pdf Oregon Department of Education (2009). Oregon Science K-HS Content Standards. Retrieved from http://www.ode.state.or.us/search/page/?id=1577

Pearson, P. D., Moje, E., Greenleaf, C. (2010). Literacy and Science: Each in the Service of the Other. Science, 328, 459-463.

Portland Public Schools (2011a). Guidelines for Local High School Reading Work Samples. Retrieved from http://www.pps.k12.or.us/departments/curriculum/4472.htm Portland Public Schools (2011b). Sample Prompts for Individualizing Your Work Samples. Retrieved from http://www.pps.k12.or.us/departments/curriculum/4472.htm

Tama, M.C \& Haley, A.M. (2007). Guiding Reading and Writing in the Content Areas: Practical Strategies. Dubuque: Kendall/Hunt Publishing Company. van Someren, M.W., Barnard, Y.F., Sandberg, J.A.C. (1994). The Think Aloud Method: A Practical Guide to Modeling Cognitive Processes. London, UK: Academic Press. 
Wade, S.E., Buxton, W.M., \& Kelley, M. (1999). Using Think-Alouds to Examine Reader-Text Interest. Reading Research Quarterly, 34(2), 194-216.

Yore, L. D., Hand, B., Goldman, S.R., Hildebrand, G.M., Osborne, J.F., Treagust, D.F., \& Wallace, C.S. (2004). New Directions in Language and Science Education Research. Reading Research Quarterly, 39(3), 347-352.

Yore, L. D. \& Hand, B.M. (2003). Examining the Literacy Component of Science Literacy: 25 Years of Language Arts and Science Research. International Journal of Science Education, 25(6), 689-725. 


\section{Appendices}

A. Instruments

i. “15 Evolutionary Gems” formatted as Science Reading Work Samples

ii. Initial and Final Survey Questions

iii. Reading Scoring Guide for Informational Text

B. Sample of Student Responses

i. Student responses from pre-assessment

ii. Student responses from post-assessment

iii. Student responses from final survey questions

C. Research Approval Documents

i. Informed consent for student participation in the study.

ii. Final Application for Human Subjects

iii. Portland State University Institutional Review Board Approval Memo

D. An Account of a Think Aloud Protocol 


\section{Appendix A: Instruments}

\section{i. “15 Evolutionary Gems" formatted as Science Reading Work Samples}

Name

Partner's name

Read the following article carefully and make notes in the margin as you read. Your notes should include:

1. Comments that show you understand the article. (A summary or statement of the main idea of the important sections may serve this purpose.)

2. Questions you have that show what you are wondering about as you read.

3. Notes that show connections you made between the information in the text to something you have studied or experienced in the past.

Clues in the Fossil Record by Stephen Marshak

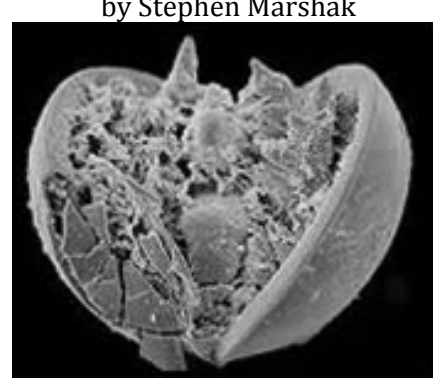

Early Cambrian fossil

Credit: Science

Paleontologists have the unenviable task of trying to piece together the history of evolution using tiny bits of information separated by huge gaps of time. This effort is particularly difficult in the Precambrian where the fossil record is exceptionally sparse. Mysteriously following this scarcity, almost all the main types of animals (or phyla) that exist today, suddenly appear in the fossil record at the beginning of the Cambrian, around 545 million years ago.

Many paleontologists concluded that an explosion of evolutionary activity during the early Cambrian must be responsible. But others aren't convinced that evolution that rapid is possible. They have suggested a longer period of evolution that left no fossil record must have preceded the Cambrian.

German and British researchers recently made a discovery that lends support to the idea that the Cambrian explosion might not
Period

Date

As you are following along, remember to mark the text:

Circle new vocabulary

Underline main idea

Write questions, predictions, connections in the margin. 
Name

Period

Partner's name

Date

have been that explosive after all, and may have been preceded by a long evolutionary fuse in the Precambrian. They found some of the oldest known crustaceans in Lower Cambrian limestone deposits in Shropshire, England. The 511 year-old fossils are very well preserved with some of the soft body parts cast in calcium phosphate, allowing them to be identified with confidence unlike other rare fossils of this age.

Crustaceans such as these, as well as modern animals like crabs, lobsters and shrimp, are members of the arthropod phylum. Previously, the oldest undoubted crustaceans were from the late Cambrian, which left 40 million years for them to evolve from a primitive arthropod at the beginning of the Cambrian. But the new discovery of early Cambrian crustaceans suggests the process must have started sooner to allow enough time for all the necessary evolutionary steps from arthropod to crustacean.

Though the newly discovered fossils are good evidence for Precambrian evolution, paleontologists would like to find an early arthropod fossil that can be identified with confidence. The search is on, but uncovering such a fossil is akin to finding the proverbial needle in a haystack. The ancestral arthropods would most certainly have been very small and lacking a shell or skeleton that could be preserved for discovery by scientists millions of years later. Still, soft animal parts may be phosphatized as in the case of the recently discovered crustaceans. In spite of the odds mounted against them, fossil hunters continue their search in hopes of finding a Precambrian piece to the evolutionary puzzle.

\section{REFERENCES}

- $\quad$ Siveter, D.J., Williams, M., Waloszek, D. 2001, A phosphatocopid crustacean with appendages from the Lower Cambrian: Science, v.293, p. 479-481. 
Name

Partner's name

Reading Performance Assessment Questions Complete the following questions in a minimum of 3 complete sentences.

1. Summarize this article for someone who had not read it.

2. Why is the discovery of the fossilized crustaceans from Lower Cambrian limestone deposits in Shropshire, England important to paleontologists?

3. Describe how fossils provide evidence for the history of evolution.

4. Does the fossil record provide a complete picture for how life evolved on Earth? Explain.

5. Do paleontologists need to find fossils that provide evidence for each stage of the evolution of life in order to understand the process of evolution?

6. Why are paleontologists interested in understanding the length of time that evolution took place?

Period

Date

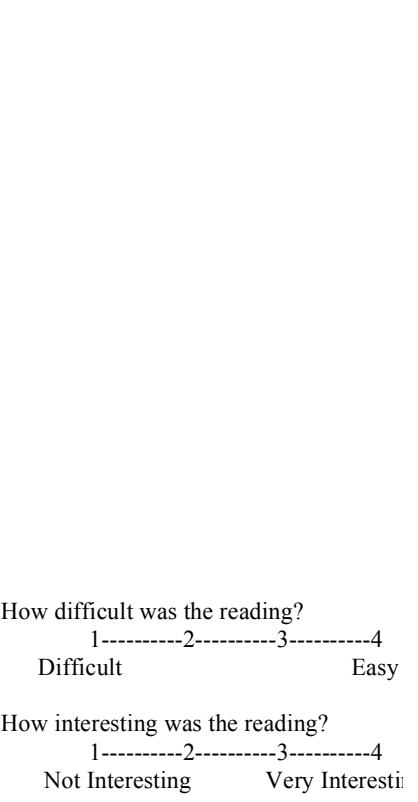


Name

Partner's name

Read the following article carefully and make notes in the margin as you read. Your notes should include:

1. Comments that show you understand the article. (A summary or statement of the main idea of the important sections may serve this purpose.)

2. Questions you have that show what you are wondering about as you read.

3. Notes that show connections you made between the information in the text to something you have studied or experienced in the past.

\section{Land-living ancestors of whales}

Fossils offer crucial clues for evolution, because they reveal the often remarkable forms of creatures long vanished from Earth. Some of them even document evolution in action, recording creatures moving from one environment to another.

Whales, for example, are beautifully adapted to life in water, and have been for millions of years. But, like us, they are mammals. They breathe air, and give birth to and suckle live young. Yet there is good evidence that mammals originally evolved on land. If that is so, then the ancestors of whales must have taken to the water at some point.

As it happens, we have numerous fossils from the first ten million years or so of whale evolution. These include several fossils of aquatic creatures such as Ambulocetus and Pakicetus, which have characteristics now seen only in whales - especially in their ear anatomy - but also have limbs like those of the land-living mammals from which they are clearly derived. Technically, these hybrid creatures were already whales. What was missing was the start of the story: the land-living creatures from which whales eventually evolved.

\section{$>$ Switch Readers}

Work published in 2007 might have pinpointed that group. Called raoellids, these now-extinct creatures would have looked like very small dogs, but were more closely related to even-toed ungulates -
Period

Date

Partner: As you are following along with the reader, remembes to mark the text:

Circle new vocabulary

Underline main idea

Write questions, predictions, connections in the margin. 
Name

Partner's name

Period

the group that includes modern-day cows, sheep, deer, pigs and

hippos. Molecular evidence had also suggested that whales and eventoed ungulates share a deep evolutionary connection.

The detailed study, by Hans Thewissen at Northeastern Ohio Universities Colleges of Medicine and Pharmacy in Rootstown and his colleagues, shows that one raoellid, Indohyus, is similar to whales, but unlike other even-toed ungulates in the structure of its ears and teeth, the thickness of its bones and the chemical composition of its teeth. These indicators suggest that this raccoonsized creature spent much of its time in water. Typical raoellids, however, had a diet nothing like those of whales, suggesting that the spur to take to the water may have been dietary change.

This study demonstrates the existence of potential transition forms in the fossil record. Many other examples could have been highlighted, and there is every reason to think that many others await discovery, especially in groups that are well represented in the fossil record.

Reference

Thewissen, J. G. M., Cooper, L. N., Clementz, M. T., Bajpai, S. \& Tiwari, B. N

Nature 450, 1190-1194 (2007)

Additional resources

Thewissen, J. G. M., Williams, E. M., Roe, L. J. \& Hussain, S. T. Nature 413, 277 -

281 (2001)

de Muizon, C. Nature 413, 259-260 (2001).

Novacek, M. J. Nature 368, 807 (1994).

Zimmer, C. At The Water's Edge (Touchstone, 1999).

Video of Thewissen's research: www.nature.com/nature/videoarchive/ancientwhale

Author website

Hans Thewissen: www.neoucom.edu/DEPTS/ANAT/Thewissen 
Name

Partner's name

Reading Performance Assessment Questions

Complete the following questions in a minimum of 3 complete sentences.

1. Summarize this article for someone who had not read it.

2. Describe how fossils provide evidence that support the theory of evolution.

3. Does the fossil record provide a complete picture for how life evolved on Earth? Explain.

4. How do scientists use fossils to describe how life has changed over time?

5. How do scientists make evolutionary connections between fossilized specimens and modern animals?

6. Explain why paleontologists are interested in finding the land-living creatures from which whales eventually evolved.
Period

Date
How difficult was the reading? 1---------2----------3----------4 Difficult Easy
How interesting was the reading? 1--------2---------3--------4 Not Interesting Very Interesti:


Name

Partner's name

Read the following article carefully and make notes in the margin as you read. Your notes should include:

1. Comments that show you understand the article. (A summary or statement of the main idea of the important sections may serve this purpose.)

2. Questions you have that show what you are wondering about as you read.

3. Notes that show connections you made between the information in the text to something you have studied or experienced in the past.

\section{Darwin's Galapagos finches}

When Charles Darwin visited the Galapagos Islands, he recorded the presence of several species of finch that all looked very similar except for their beaks. Ground finches have deep and wide beaks; cactus finches have long, pointed beaks; and warbler finches have slender, pointed beaks, reflecting differences in their respective diets.

Darwin speculated that all the finches had a common ancestor that had migrated to the islands. Close relatives of the Galapagos finches are known from the South American mainland, and the case of Darwin's finches has since become the classic example of how natural selection has led to the evolution of a variety of forms adapted to different ecological niches from a common ancestral species - termed 'adaptive radiation'.

This idea has since been reinforced by data showing that even small differences in the depth, width or length of the beak can have major consequences for the overall fitness of birds. To find out what genetic mechanisms underlie the changes in beak shape that mark each species, Harvard University's Arhat Abzhanov and his colleagues examined numerous genes that are switched on in the developing beaks of finch chicks; their study was published in 2006.

\section{Switch Readers.}

The researchers discovered that shape differences coincide with differing expression of the gene for calmodulin, a molecule involved in calcium signalling that is vital in many aspects of development and metabolism. Calmodulin is expressed more strongly in the long and pointed beaks of cactus finches than in the more robust beaks of other species.
Period

Date

Partner: As you are following along with the reader, remembes to mark the text:

Circle new vocabulary

Underline main idea

Write questions, predictions, connections in the margin. 
Name

Partner's name

Period

Artificially boosting the expression of calmodulin in the embryonic tissues that give rise to the beak causes an elongation of the upper beak, similar to that seen in cactus finches.

The results show that at least some of the variation in beak shape in Darwin's finches is likely to be related to variation in calmodulin activity, and implicates calmodulin in the development of craniofacial skeletal structures more generally. The study shows how biologists are going beyond the mere documentation of evolutionary change to identify the underlying molecular mechanisms.

Reference

Abzhanov, A. et al. Nature 442, 563-567 (2006).

Author websites

Clifford Tabin: http://www.hms.harvard.edu/dms/bbs/fac/tabin.html

Peter Grant:

http://www.eeb.princeton.edu/FACULTY/Grant_P/grantPeter.html 
Name

Partner's name

Reading Performance Assessment Questions

Complete the following questions in a minimum of 3 complete sentences.

1. Summarize this article for someone who had not read it.

2. Describe Darwin's observations of the finches of the Galapagos Islands.

3. Explain how Darwin's finches serve as an example of natural selection.

4. How do scientists use the study of Darwin's finches as evidence that supports evolutionary theory?

5. What is the role of genetics in the evolution of a species?

6. Explain why evolutionary biologists are interested in discovering the mechanisms of evolution.
Period

Date

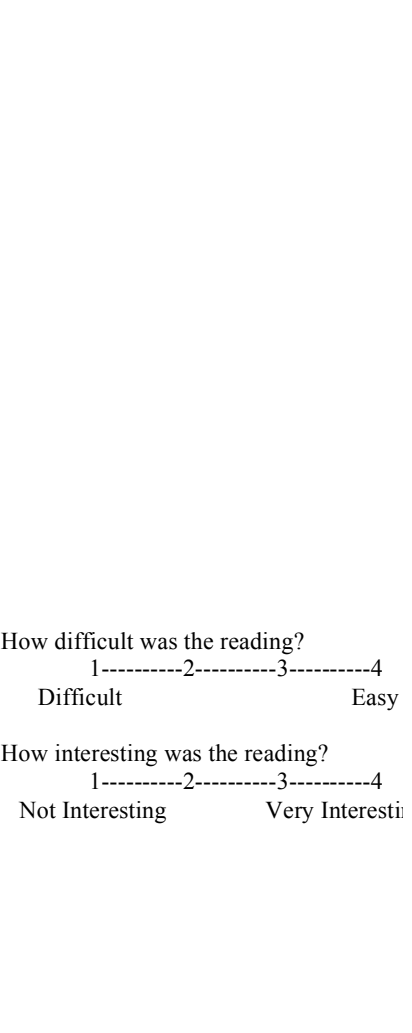


Name

Partner's name

Read the following article carefully and make notes in the margin as you read. Your notes should include:

1. Comments that show you understand the article. (A summary or statement of the main idea of the important sections may serve this purpose.)

2. Questions you have that show what you are wondering about as you read.

3. Notes that show connections you made between the information in the text to something you have studied or experienced in the past.

\section{The origin of feathers}

One of the objections to Charles Darwin's theory of evolution was the lack of 'transitional forms' in the fossil record forms that illustrated evolution in action, from one major group of animals to another. However, hardly a year after the publication of On the Origin of Species, an isolated feather was discovered in Late Jurassic (about 150 million years old) lithographic limestones of Solnhofen in Bavaria, followed in 1861 by the first fossil of Archaeopteryx, a creature with many primitive, reptilian features such as teeth and a long, bony tail - but with wings and flight feathers, just like a bird.

Although Archaeopteryx is commonly seen as the earliest known bird, many suspected that it was better seen as a dinosaur, albeit one with feathers. Thomas Henry Huxley, Darwin's colleague and friend, discussed the possible evolutionary link between dinosaurs and birds, and palaeontologists speculated, if wildly, that dinosaurs with feathers might one day be found.

In the 1980s, deposits from the early Cretaceous period (about 125 million years ago) in the Liaoning Province in northern China vindicated these speculations in the most dramatic fashion, with discoveries of primitive birds in abundance alongside dinosaurs with feathers, and feather-like plumage.

\section{$>$ Switch Readers.}

Starting with the discovery of the small theropod Sinosauropteryx by Pei-ji Chen from China's Nanjing Institute of Geology and Palaeontology and his colleagues, a variety of feather-clad forms have been found. Many of these feathered dinosaurs could not possibly have flown, showing that feathers first evolved for reasons other than flight, possibly for sexual display or thermal insulation, for instance. In 2008, Fucheng Zhang and his colleagues from the Chinese Academy of
Period

Date

Partner: As you are following along with the reader, remembes to mark the text:

Circle new vocabulary
Underline main idea
Write questions, predictions,
connections in the margin.


Name

Partner's name

Period

Sciences in Beijing announced the bizarre creature

Epidexipteryx, a small dinosaur clad in downy plumage, and sporting four long plumes from its tail. Palaeontologists are now beginning to think that their speculations weren't nearly wild enough, and that feathers were indeed quite common in dinosaurs.

The discovery of feathered dinosaurs not only vindicated the idea of transitional forms, but also showed that evolution has a way of coming up with a dazzling variety of solutions when we had no idea that there were even problems. Flight could have been no more than an additional opportunity that presented itself to creatures already clothed in feathers.

References Chen, P.-J., Dong, Z.-M. \& Zhen, S.-N. Nature 391, 147-152 (1998). Zhang, F., Zhou, Z., Xu, X., Wang, X. \& Sullivan, C. Nature 455, 1105-1008 (2008).

Additional resources

Gee, H. (ed.) Rise of the Dragon (Univ. Chicago Press, 2001). Chiappe, L Glorified dinosaurs (Wiley-Liss, 2007). Gee, H. \& Rey, L. V. A Field Guide to Dinosaurs (Barron's Educational, 2003). 
Name

Partner's name

Reading Performance Assessment Questions

Complete the following questions in a minimum of 3 complete sentences.

1. Summarize this article for someone who had not read it.

2. Describe the fossil evidence for the origin of the feather.

3. Explain how the evolution of the feather serves as an evidence for evolution.

4. Why is the discovery of Archaeopteryx important to scientists studying evolution?

5. Did the organisms with feathers found in the fossil record fly? What evidence do scientists have to support this claim?

6. Explain why evolutionary biologists are interested in finding the origin of the feather.
Period

Date

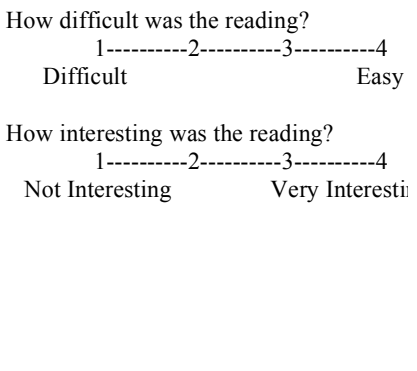


Name

Partner's name

Read the following article carefully and make notes in the margin as you read. Your notes should include:

1. Comments that show you understand the article. (A summary or statement of the main idea of the important sections may serve this purpose.)

2. Questions you have that show what you are wondering about as you read.

3. Notes that show connections you made between the information in the text to something you have studied or experienced in the past.

\section{Natural selection in speciation}

Evolutionary theory predicts that divergent natural selection will often have a key role in speciation. Working with sticklebacks (Gasterosteus aculeatus), Jeffrey McKinnon at the University of Wisconsin in Whitewater and his colleagues reported in 2004 that reproductive isolation can evolve as a by-product of selection on body size. This work provides a link between the build-up of reproductive isolation and the divergence of an ecologically important trait.

The study was done on an extraordinary geographical scale, involving mating trials between fish taken in Alaska, British Columbia, Iceland, the United Kingdom, Norway and Japan. It was underpinned by molecular genetic analyses that provided firm evidence that fish that have adapted to living in streams had evolved repeatedly from marine ancestors, or from fish that live in the ocean but return to fresh water to spawn. Such migratory populations in the study had larger bodies on average than did those living in streams. Individuals tended to mate with fish of a similar size, which accounts well for the reproductive isolation between different stream ecotypes and their close, seafaring neighbors.

\section{$>$ Switch readers}

Taking into account the evolutionary relationships, a comparison of the various types of stickleback, whether stream or marine, strongly supports the view that adaptation to different environments brings about reproductive isolation. The researchers' experiments also confirmed the connection between size divergence and the build-up of reproductive isolation - although traits other than size also contribute to reproductive isolation to some extent.

Reference McKinnon, J. S. et al. Nature 429, 294-298 (2004)

Additional resources Gillespie, R. G. \& Emerson, B. C. Nature 446, 386-387 (2007). Kocher, T. D. Nature 435, 29-30 (2005). Emerson, B. C. \& Kolm, N. Nature 434, 1015-1017 (2005), Author websites

Jeffrey McKinnon: http://facstaff.uww.edu/mckinnoj/mckinnon.html David Kingsley:

http://kingsley.stanford.edu Dolph Schluter: http://www.zoology.ubc.ca/ schluter
Period

Date

Partner: As you are following along with the reader, remembes to mark the text:

Circle new vocabulary

Underline main idea

Write questions, predictions, connections in the margin 
Name

Partner's name

Reading Performance Assessment Questions

Complete the following questions in a minimum of 3 complete sentences.

1. Summarize this article for someone who had not read it.

2. Describe how reproductive isolation in sticklebacks led to speciation.

3. What ecologically important trait changed over time in the stickleback population?

4. Explain how the evolution of the stickleback as an evidence for evolution.

5. How do scientists use molecular genetics to study evolution?

6. How do populations of organisms adapt to new environments?
Period

Date 
Name

Partner's name

Read the following article carefully and make notes in the margin as you read. Your notes should include:

1. Comments that show you understand the article. (A summary or statement of the main idea of the important sections may serve this purpose.)

2. Questions you have that show what you are wondering about as you read.

3. Notes that show connections you made between the information in the text to something you have studied or experienced in the past.

\section{From water to land}

The animals we are most familiar with are tetrapods - they are vertebrates (they have backbones) and they live on land. That includes humans, almost all domestic animals and most of the wild ones that any child would recognize: mammals, birds, amphibians and reptiles. The vast majority of vertebrates, however, are not tetrapods, but fish. There are more kinds of fish, in fact, than all the species of tetrapods combined. Indeed, through the lens of evolution, tetrapods are just one branch of the fish family tree, the members of which just happen to be adapted for life out of water.

The first transition from water to land took place more than 360 million years ago. It was one of the most demanding such moves ever made in the history of life. How did fins become legs? And how did the transitional creatures cope with the formidable demands of land life, from a desiccating environment to the crushing burden of gravity?

It used to be thought that the first landlubbers were stranded fish that evolved to spend more and more time ashore, returning to water to reproduce. Over the past 20 years, palaeontologists have uncovered fossils that have turned this idea upside down. The earliest tetrapods, such as Acanthostega from eastern Greenland around 365 million years ago, had fully formed legs, with toes, but retained internal gills that would soon have dried out in any long stint in air. Fish evolved legs long before they came on land. The earliest tetrapods did most of their evolving in the more forgiving aquatic environment. Coming ashore seems to have been the very last stage.

\section{Switch readers}

Researchers suspect that the ancestors of tetrapods were creatures called elpistostegids. These very large, carnivorous, shallow-water fish would have looked and behaved much like alligators, or giant salamanders. They looked like tetrapods in many respects, except that they still had fins. Until recently,
Period

Date

Partner: As you are following along with the reader, remembe1 to mark the text:

Circle new vocabulary

Underline main idea

Write questions, predictions, connections in the margin. 
Name

Partner's name

Period

elpistostegids were known only from small fragments of fossils that were poorly preserved, so it has been hard to get a rounded picture of what they were like.

In the past couple of years, several discoveries from Ellesmere Island in the Nunavut region of northern Canada have changed all that. In 2006, Edward Daeschler and his colleagues described spectacularly well- preserved fossils of an elpistostegid known as Tiktaalik that allow us to build up a good picture of an aquatic predator with distinct similarities to tetrapods - from its flexible neck, to its very limb-like fin structure.

The discovery and painstaking analysis of Tiktaalik illuminates the stage before tetrapods evolved, and shows how the fossil record throws up surprises, albeit ones that are entirely compatible with evolutionary thinking.

References Daeschler, E. B., Shubin, N. H. \& Jenkins, F A. Nature 440, 757-763 (2006) Shubin, N. H., Daeschler, E. B., \& Jenkins, F A. Nature 440, 764-771 (2006).

Additional resources Ahlberg, P. E. \& Clack, J. A. Nature 440, 747-749 (2006). Clack,

Gaining Ground (Indiana Univ. Press, 2002) Shubin, N. Your Inner Fish (Allen Lane, 2008) Gee, H. Deep Time (Fourth Estate, 2000) Tiktaalik homepage:

http://tiktaalik.uchicago.edu

Author websites

Edward Daeschler: http://www.ansp.org/research/biodiv/vert_paleo/staff.php Neil Shubin: http://pondside.uchicago.edu/oba/faculty/shubin_n.html 
Name

Partner's name

Reading Performance Assessment Questions

Complete the following questions in a minimum of 3 complete sentences.

1. Summarize this article for someone who had not read it.

2. Describe the physiological challenges to living on land that tetrapods overcame in order to transition from water to land.

3. Why do scientists think that tetrapods evolved from aquatic animals?

4. What evidence from the fossil record provides evidence for the evolution of tetrapods?

5. Explain how the transition of tetrapods from water to land is important as an evidence for evolution.

6. How do populations of organisms adapt to new environments?
Period

Date

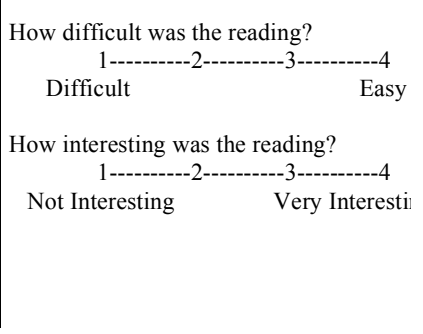


Name

Partner's name

Read the following article carefully and make notes in the margin as you read. Your notes should include:

1. Comments that show you understand the article. (A summary or statement of the main idea of the important sections may serve this purpose.)

2. Questions you have that show what you are wondering about as you read.

3. Notes that show connections you made between the information in the text to something you have studied or experienced in the past.

\section{Evolutionary history matters}

Evolution is often thought to be about finding optimal solutions to the problems that life throws up. But natural selection can only work with the materials at hand - materials that are themselves the results of many millions of years of evolutionary history. It never starts with a blank slate. If that were the case, then tetrapods faced with the task of moving on land would not have had their fins transform into legs; they might perhaps have evolved wheels.

A real-life case of the ingenuity of adaptation concerns a moray eel (Muraena retifera), a long, snake-like reef predator.

Historically, bony fish use suction to catch their prey. A fish approaching food opens its mouth wide to create a large cavity into which prey and water flood. As the excess water leaves through the gills, the fish sucks the prey down into its throat and pharyngeal jaws, a second set of jaws and teeth derived from the skeleton that supports the gills. But morays have a problem because of their elongated, narrow shape.

Even with their jaws agape, their mouth cavity is too small to generate enough suction to carry prey to their pharyngeal jaws. The solution to this conundrum was documented in 2007.

\section{Switch Readers}

Through careful observation and X-ray cinematography, Rita Mehta and Peter Wainwright from the University of California, Davis, discovered evolution's breathtaking solution. Rather than prey coming to the pharyngeal jaws, the pharyngeal jaws move forwards into the mouth cavity, trapping the prey and dragging it backwards. This, the researchers say, is the first described case of a vertebrate using a second set of jaws to both restrain and transport prey, and is the only known alternative to the hydraulic prey transport reported in most bony fish - a major innovation that could have contributed to the success of moray eels as predators.
Period

Date

Partner: As you are following along with the reader, remembe1 to mark the text:

Circle new vocabulary

Underline main idea

Write questions, predictions, connections in the margin. 
Name

Partner's name

Period

Date

The mechanics of the moray's pharyngeal jaws are reminiscent of the ratchet mechanisms used by snakes - also long, thin and highly predatory creatures. This is an instance of convergence, the evolutionary phenomenon in which distantly related creatures evolve similar solutions to common problems. This study demonstrates the contingent nature of evolution; as a process it does not have the luxury of 'designing from scratch'.

Reference

Mehta, R. S. \& Wainwright, P. C. Nature 449, 79-82 (2007).

Additional resource

Westneat, M. W. Nature 449, 33-34 (2007).

Author websites

Rita Mehta: http://www.eve.ucdavis.edu/ wainwrightlab/rsmehta/index.html

Peter Wainwright: http://www.eve.ucdavis.edu/ wainwrightlab 
Name

Partner's name

Reading Performance Assessment Questions

Complete the following questions in a minimum of 3 complete sentences.

1. Summarize this article for someone who had not read it.

2. Describe how the moray eel is adapted to its environment.

3. Explain how natural selection selected for certain adaptive traits that existed in ancestors of the moray eel.

4. How are mechanics of the moray's pharyngeal jaws an example of evolutionary convergence?

5. What is the role of natural selection in the evolution of a species?

6. Explain how the mechanics of the moray eel's jaw supports the scientific theory of evolution.
Period

Date
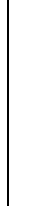

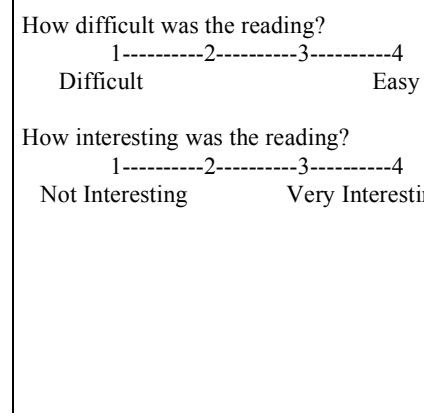


Name

Partner's name

Read the following article carefully and make notes in the margin as you read. Your notes should include:

4. Comments that show you understand the article. (A summary or statement of the main idea of the important sections may serve this purpose.)

5. Questions you have that show what you are wondering about as you read.

6. Notes that show connections you made between the information in the text to something you have studied or experienced in the past.

\section{Toxin resistance in snakes and clams}

Biologists are increasingly coming to understand the molecular mechanisms that underlie adaptive evolutionary change. In some populations of the newt Taricha granulosa, for example, individuals accumulate the nerve poison tetrodotoxin in their skin, apparently as a defense against garter snakes (Thamnophis sirtalis).

Garter snakes that prey on the newts that produce tetrodotoxin have evolved resistance to the toxin. Through painstaking work, Shana Geffeney at the Stanford School of Medicine in California and her colleagues uncovered the underlying mechanism; their study was published in 2005. Variation in the level of resistance of garter snakes to their newt prey can be traced to molecular changes that affect the binding of tetrodotoxin to a particular sodium channel.

\section{Switch readers}

Similar selection for toxin resistance apparently occurs in softshell clams (Mya arenaria) in areas of the North American Atlantic coast, as reported by Monica Bricelj at the Institute for Marine Biosciences in Nova Scotia, Canada, and her colleagues in the same issue of Nature. The algae that produce 'red tides' generate saxitoxin - the cause of paralytic shellfish poisoning in humans. Clams are exposed to the toxin when they ingest the algae. Clams from areas subject to recurrent red tides are relatively resistant to the toxin and accumulate it in their tissues. Clams from unaffected areas have not evolved such resistance.

Resistance to the toxin in the exposed populations is correlated with a single mutation in the gene that encodes a sodium channel, at a site already implicated in the binding of saxitoxin. It seems likely, therefore, that the saxitoxin acts as a potent selective agent in the clams and leads to genetic adaptation.
Period

Date

Partner: As you are following along with the reader, remembes to mark the text:

Circle new vocabulary
Underline main idea
Write questions, predictions,
connections in the margin.


Name

Partner's name

These two studies show how similar selective pressures can lead to similar adaptive responses even in very different taxa.

References

Geffeney, S. L., Fujimoto, E., Brodie, E. D., Brodie, E. D. Jr, \& Ruben, P. C. Nature 434, 759

763 ( 2005)

Bricelj, V. M. et al. Nature 434, 763-767 (2005).

Additional resources

Mitchell-Olds, T. \& Schmitt, J. Nature 441, 947-952 (2006)

Bradshaw, H. D. \& Schemske, D. W. Nature 426, 176-178 (2003)

Coltman, D. W., O'Donoghue, P, Jorgenson, J. T., Hogg, J. T. Strobeck, C. \& Festa-Bianchet,

M. Nature 426, 655-658 (2003).

Harper Jr, G. R. \& Pfennig, D. W. Nature 451, 1103-1106 (2008)

Ellegren, H. \& Sheldon, B. Nature 452, 169-175 (2008).

Author websites

Shana Geffeney: http://wormsense.stanford.edu/people.htm

Monica Bricelj: http://marine.biology.dal.ca/Faculty_Members/Bricelj,_Monica.php
Period

Date 
Name

Partner's name

Reading Performance Assessment Questions

Complete the following questions in a minimum of 3 complete sentences.

7. Summarize this article for someone who had not read it.

8. Describe how the evolutionary relationship between the garter snakes and the newts described in the article.

9. Explain how certain softshell clam populations are resistant to saxitoxin while others are not.

10. What is the molecular process that allows garter snakes to be resistant to tetrodotoxin?

11. How do these two studies show how similar selective pressures can lead to similar adaptive responses even in very different organisms?

12. Explain how these instances of toxin resistance in snakes and clams support the scientific theory of evolution.
Period

Date

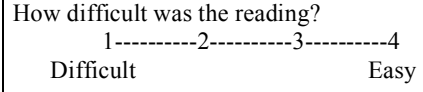

How interesting was the reading? 1--------2---------3---------4 Not Interesting Very Interesti] 
ii. Survey Questions

Interview questions used before the pre-assessment:

1. When you are reading informational text, how often do you pause to check for understanding?

2. How often do you pause on unfamiliar vocabulary and try to predict the meaning of a word or look for clues of the meaning in the text?

3. How often do you think about the connection between the information in the text to something you have studied or experienced in the past?

4. How does it change your understanding of how to read text when a teacher demonstrates a technique like the think aloud?

5. Did you find the text difficult? Did you find the text interesting? 
Interview questions used after the post-assessment:

i. When you are reading informational text, how often do you pause to check for understanding?

a. When you do pause and check for understanding, how does it help you?

b. Has the frequency changed since using the think aloud protocol?

ii. How often do you pause on unfamiliar vocabulary and try to predict the meaning of a word or look for clues of the meaning in the text?

a. Has the frequency changed since using the think aloud protocol?

iii. How often do you think about the connection between the information in the text to something you have studied or experienced in the past?

a. Has the frequency changed since using the think aloud protocol?

iv. How does it change your understanding of how to read text when a teacher demonstrates a technique like the think aloud?

v. Did you find the text difficult? Did you find the text interesting?

a. How does that change the way that you read informational text? 
iii. Reading Scoring Guide for Informational Text

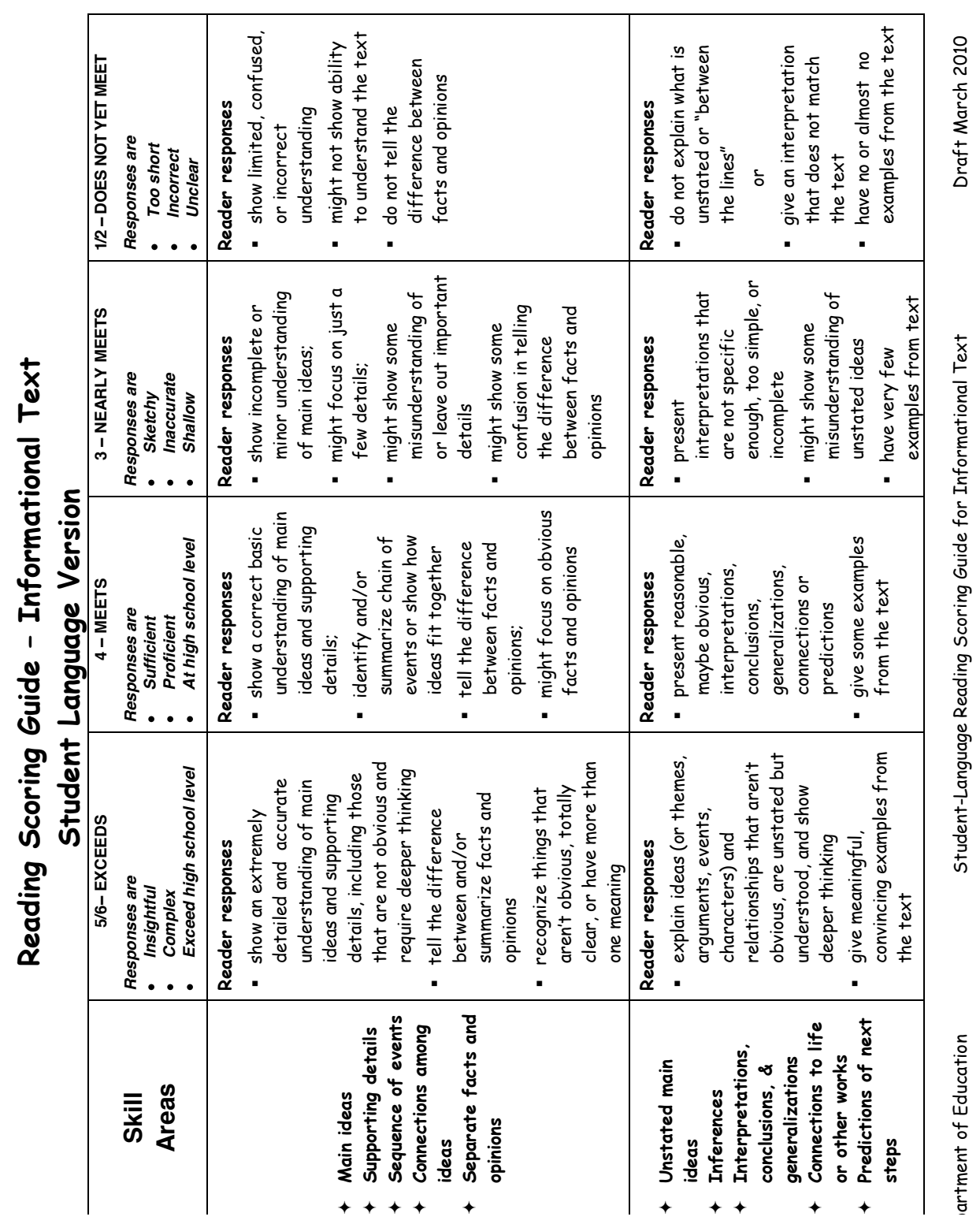




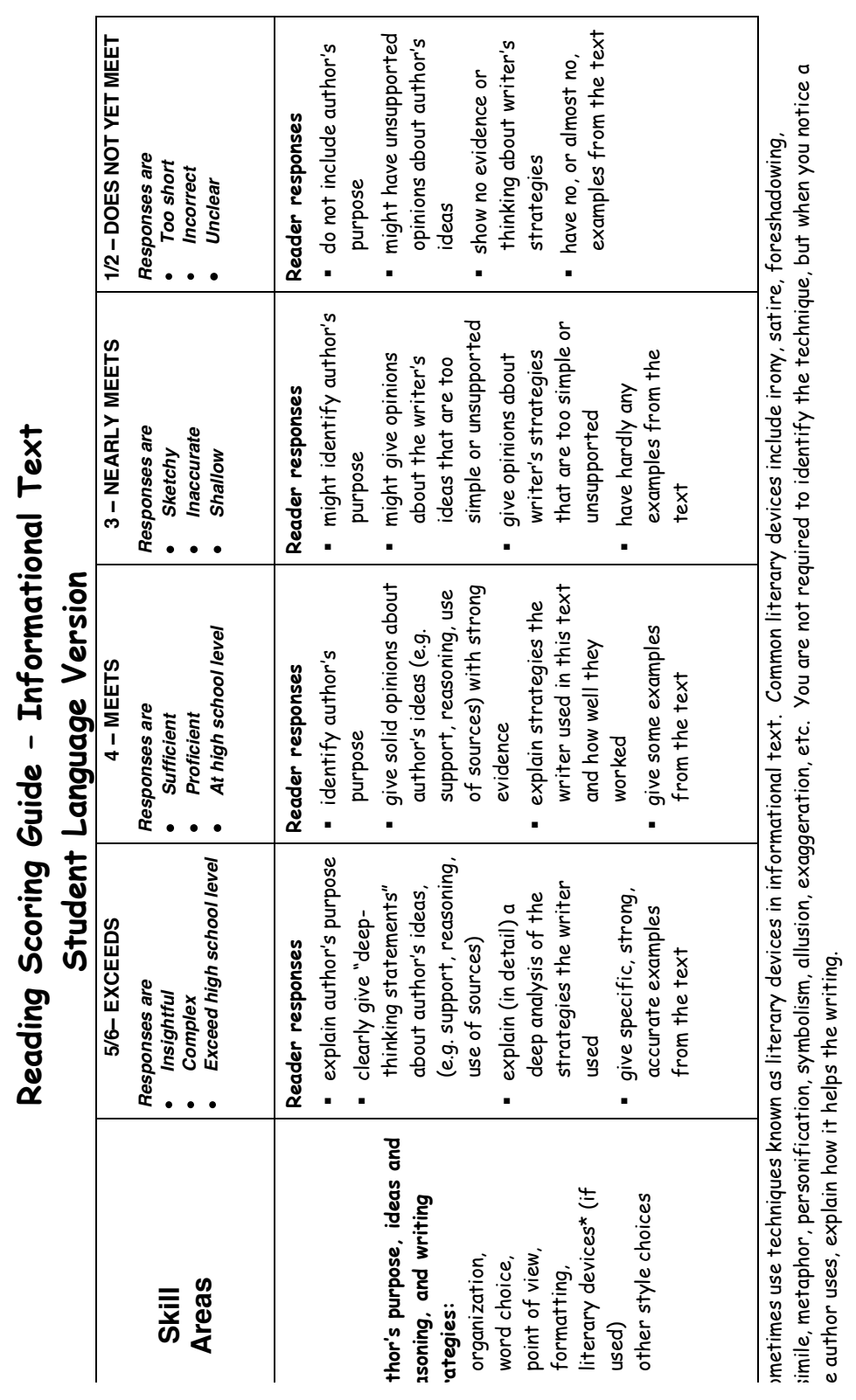

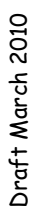




\section{Appendix B: Sample of Student Responses}

i. Student responses from pre-assessment

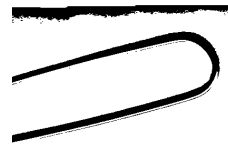

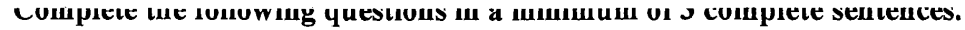

1. Summarize this article for someone who has not read it.

Hey are tying to figure out why most of the anillats living today shaved up sus million yedsago

2. Why is the discovery of the fossilized crustaceans from Lower Cambrian limestone

The fossis they found al very will pleserved and this allows then to Identify then with confidence.

3. Describe how fossils provide evidence for the history of evolution. The sutt body, past cast in Cacium fhosphate dlows $r$ then to tedentity.

4. Does the fossil record provide a complete picture for how life evolved on Earth? Explain.No, It is Still Pptty wollewaven Paleantologist

5 . ne sfrugyling for the right answer.

6. Do paleontologists need to find fossils that provide evidence for each stage of the evolution of life in order to understand the process of evolution? iyes they would like to find an ealy anthlopod Eossil. those fossis an be easily Identifled.

7. Why are paleontologists interested in understanding the length of time that evolution took place?

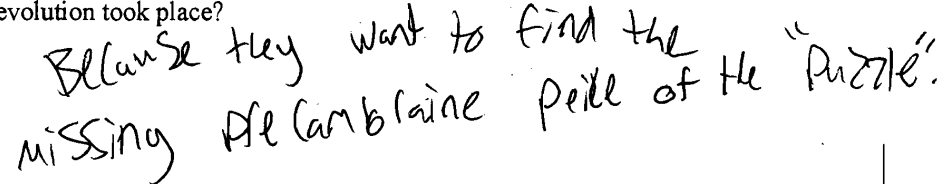

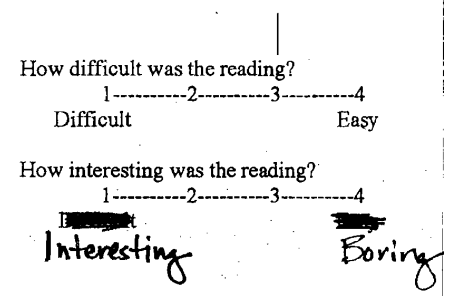


Name

Period

Partner's name

Date

Reading Performance Assessment Questions

Complete the following questions in a minimum of 3 complete sentences.

1. Summarize this article for someone who has not read it.

Pateontoligists under the trilty over ai wein

a hypothesis on whether or not there cowe tom. crepos

2. Why is the discovery of the fossilized crustaceans from Lower Cambrian limestone deposits in Shropshire, England important to paleontologists?

the idea-uas true.

3. Describe how fossils provide evidence for the history of evolution.

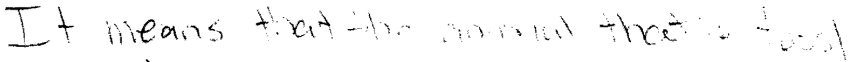

was real

4. Does the fossil record provide a complete picture for how life evolved on Earth? Explain.

5. 50 it's onlu COC wat?

6. Do paleontologists need to find fossils that provide evidence for each stage of the evolution of life in order to understand the process of evolution?

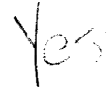

$Y$

7. Why are paleontologists interested in understanding the length of time that evolution took place?

$$
r a t \text { and acost tine }
$$

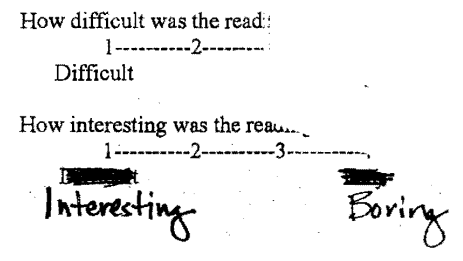


Name

Period

Partner's name

Date

Reading Performance Assessment Questions

Complete the following questions in a minimum of 3 complete sentences.

1. Summarize this article for someone who has not read it.

$$
\begin{aligned}
& \text { incy foond some fasits from lobster and at } \\
& \text { and they coone out how ingy are hdisa } \\
& \text { a tosil costonce }
\end{aligned}
$$

2. Why is the discovery of the fossilized crustaceans from Lower Cambrian limestone deposits in Shropshire, England important to paleontologists?

$$
\begin{aligned}
& \text { Because its to sep whu happen } \\
& \text { back than its a partof histerg }
\end{aligned}
$$

3. Describe how fossils provide evidence for the history of evolution

$$
\text { Beciuse it isc. Sllyer fo.sil }
$$

4. Does the fossil record provide a complete picture for how life evolved on Earth? Explain.

5. no beekuse ( Skow US a por

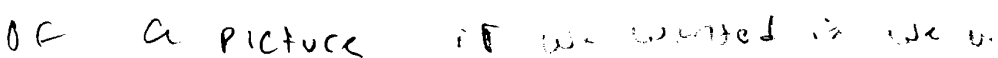

$$
\text { have to see our }=1 \mathrm{fs}
$$

6. Do paleontologists need to find fossils that provide evidence for each stage of the evolution of life in order to understand the process of evolution?

$$
\begin{aligned}
& \text { yes becauseit is a port of wbing It: } \\
& \text { Shaws us what happen bucle then. }
\end{aligned}
$$

7. Why are paleontologists interested in understanding the length of time that evolution took place?

$$
\begin{aligned}
& \text { Becurse helps Ecse whut huppon } \\
& \text { buck than whd aso whet animalsell } \\
& \text { back in } h \text { isfory. } \\
& \begin{array}{l}
\text { How difficult was the reading } \\
1------2-\cdots---3 \\
\text { Difficult }
\end{array} \\
& \begin{array}{l}
\text { How interesting was the readi } \\
\text { Difficult }
\end{array}
\end{aligned}
$$


Name

Partner's name

Period

Date

\section{Reading Performance Assessment Questions}

Complete the following questions in a minimum of 3 complete sentences.

1. Summarize this article for someone who has not read it.

It's apay spectes in the cambrian ane and yieer evalution. The scientisys art looking Sor placo pray the species existed before, and

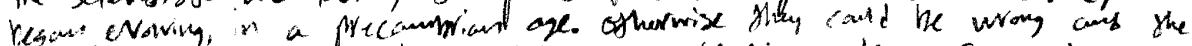

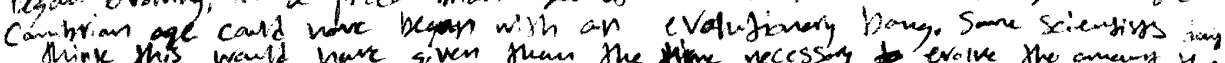
2. Why is the discovery of the fossilized crustaceans from Lower Cambrian limestone the amany ding deposits in Shropshire, England important to paleontologists?

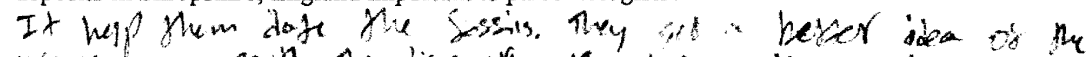

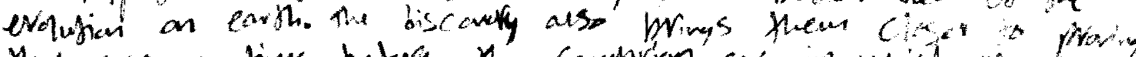

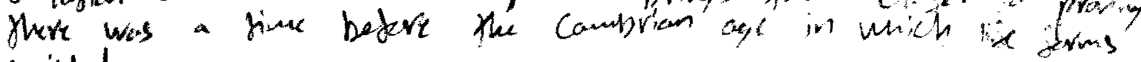
exisyed.

3. Describe how fossils provide evidence for the history of evolution.

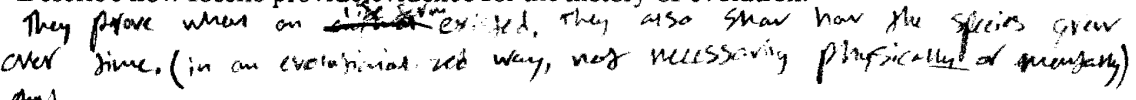
And

4. Does the fossil record provide a complete picture for how life evolved on Earth? Explain. No, ir ally provides a picture ar hav life kuarri to us

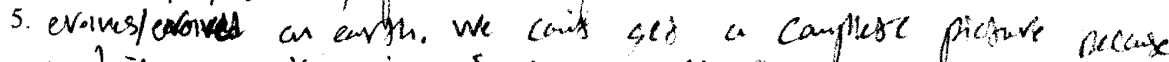

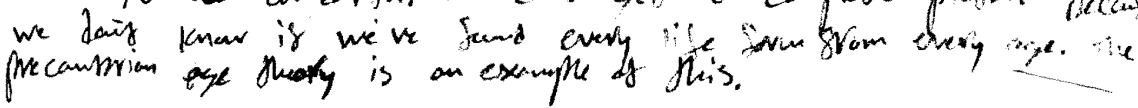

6. Do paleontologists need to find fossils that provide evidence for each stage of the evolution of life in order to understand the process of evolution?

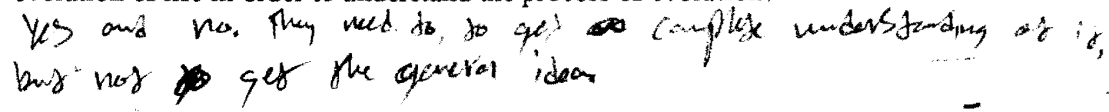

7. Why are paleontologists interested in understanding the length of time that evolution took place?

toyre col whey lived an eargh

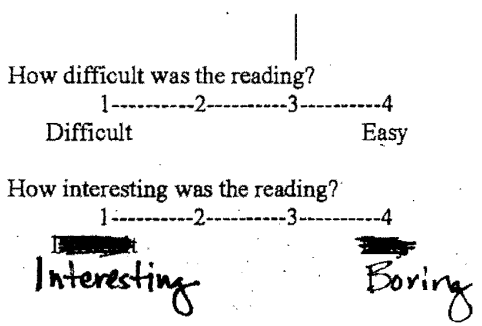


Name

Period

Partner's name

Date

\section{Reading Performance Assessment Questions}

Complete the following questions in a minimum of 3 complete sentences.

1. Summarize this article for someone who has not read it.

Peleontolugists rew disculery; sil year old cructacean w/soft

body parts-clowly unconeing clues to the part lpere comoran

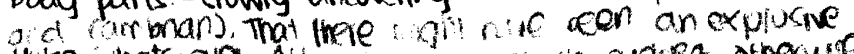

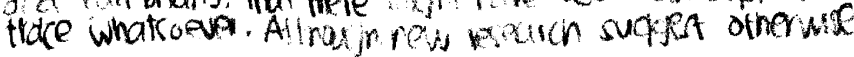

2. Why is the discovery of the fossilized crustaceans from Lower Cambrian limestone deposits in Shropshire, England important to paleontologists?

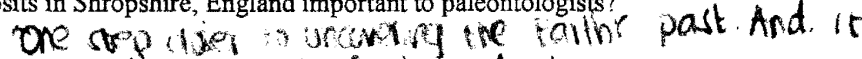

is the oidest crustacen osw tourd, yet

3. Describe how fossils provide evidence for the history of evolution

Allow us to campone the moden pis of an

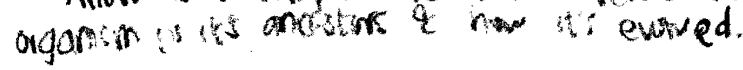

4. Does the fossil record provide a complete picture for how life evolved on Earth? Explain.

5. Mayle not a complete picture irte we stim rave

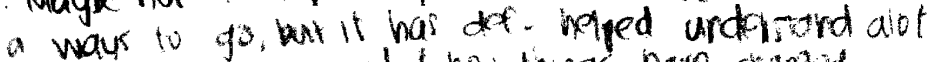

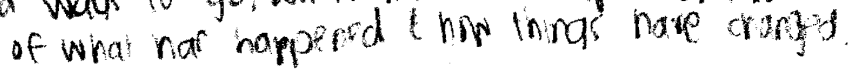

6. Do paleontologists need to find fossils that provide evidence for each stage of the evolution of life in order to understand the process of eyolution?

Maybe nit each stage, but iust enough.

7. Why are paleontologists interested in understanding the length of time that evolution took place?

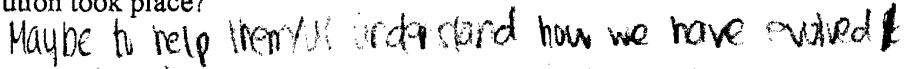

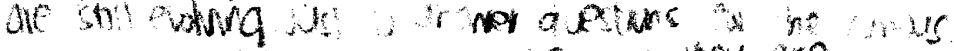

To know whow mog we ine way they are.

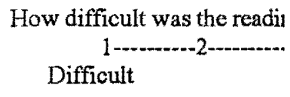

How interesting was the rea

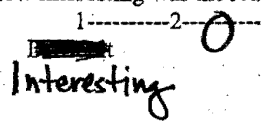


Complete the following questions in a minimum of 3 complete sentences.

1. Summarize this article for someone who has not read it.

There was an explosion of life-forms at the begining of the cambrien. Some scientists belleved that rapid

evolution took place, but after thoy found crestaceon fossils from the lower combien, thell believe evolution toor place pre cambien.

2. Why is the discovery of the fossilized crustaceans from Lower Cambrian limestone deposits in Shropshire, England important to paleontologists?

Because it supported the theory of evolution before the cambrien precamblan.

3. Describe how fossils provide evidence for the history of evolution.

Fossils show how an animal looked/develuped,

functions, and similaritles between fossils can snow thew are related species that evolved rehanged).

4. Does the fossil record provide a complete picture for how life evolved on Earth? Explain.

5. No, the fossil record doesnt show a comple te picture for how life evolved, becculse some fossils are missing.

6. Do paleontologists need to find fossils that provide evidence for each stage of the evolution of life in order to understand the process of evolution?

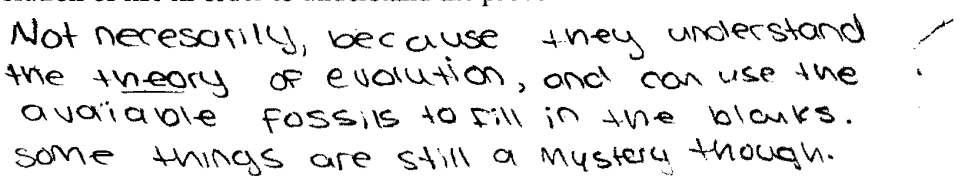

7. Why are paleontologists interested in understanding the length of time that evolution took place?

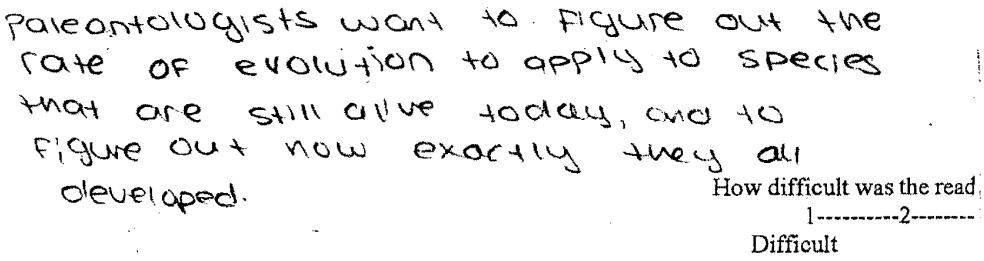

How interesting wasther

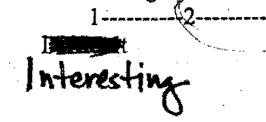




\section{Name}

Period

Partner's name

Date.

Reading Performance Assessment Questions

Complete the following questions in a minimum of 3 complete sentences.

1. Summarize this article for someone who has not read it.

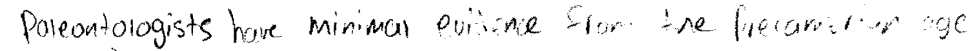

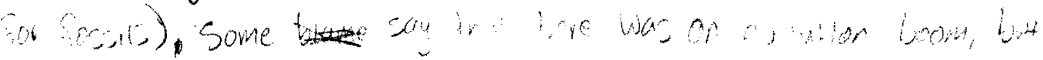

Others dicagree. Germand British reseachers foand a clustaccon from 545 m yrs ago,

2. Why is the discovery of the fossilized crustaceans from Lower Cambrian limestone on dir yir the deposits in Shropshire, England important to paleontologists?

It Shows that there was, in fock, erough time fol the

a Processes of enousion to ocaur.

3. Describe how fossils provide evidence for the history of evolution

older Sossils compred to yourer fosins the same reanimy. can show minute changes/differences, showirs that as time goes m, plontion

occurs by naturai selegtion.

4. Does the fossil record provide a complete picture for how life evolved on Earth? Explain.

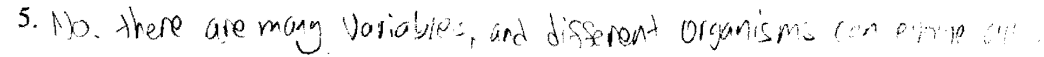

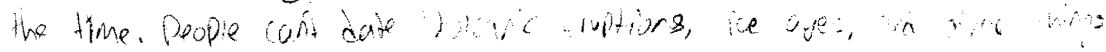
based solely on fossil lecords

6. Do paleontologists need to find fossils that provide evidence for each stage of the evolution of life in order to understand the process of evolution?

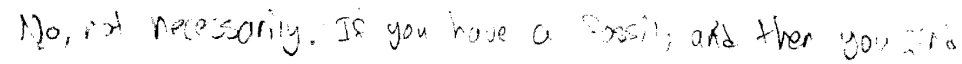

"Aso munch yonager fossi of the same organism, which has evoved,

Paleontoloyists can fill ir the blanks from experience of ther organims.

7. Why are paleontologists interested in understanding the length of time that evolution took place?

$$
\text { It's froinating to think civout and know awont, it can make is }
$$

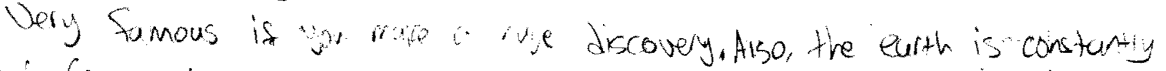

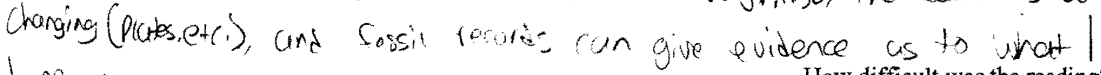

hophenol and difficult was the reading?

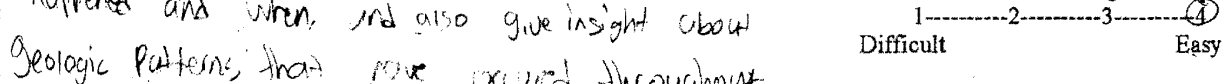

Earbs nistory aud throughout How interesting was the reading?

(1-2)

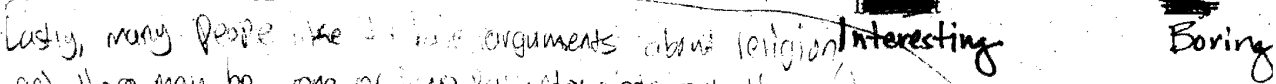

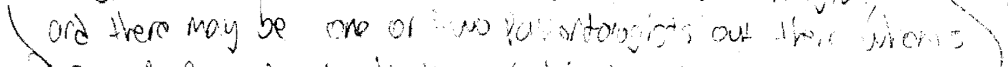

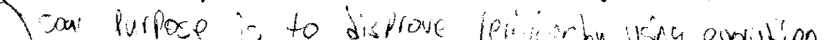




\section{ii. Student responses from post-assessment}

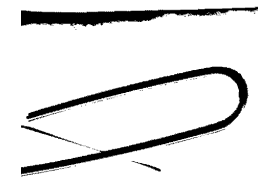

Complete the following questions in a minimum of 3

complete sentences.

1. Summarize this article for someone who had not read it.

clams who eatalgae, and people who eat The clams get

the toxin. and llow garter snaves became tolerant

2. Describe tow the evoltumang relationship between the they recase

garter snakes and the newts described in the article.

The garter sinave always preyed upon newts, and their defence mecrianism was to release a Toxin, that

3. Exp snave later beca me tolera nt too.

resistant to saxitoxin while others are not.

- bicause some aigue is eaten mure constantly

than others.

4. What is the molecular process that allows garter snakes to be resistant to tetrodotoxin?

They gothine genelations or ifirgsting " triey soon just get used to it

5. How do these two studies show how similar selective pressures can lead to similar adaptive responses even in very different organisms?

They all eat the Things twey need to eat and if there is a toxin, They should adapt to it.

6. Explain how these instances of toxin resistance in snakes and clams support the scientific theory of evolution.

- They eat these overtime so much, they get used,

to $\mathrm{H}$

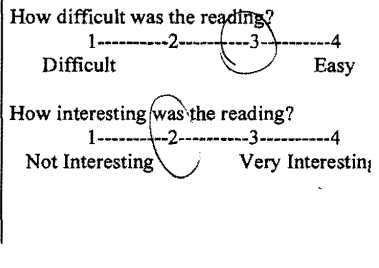




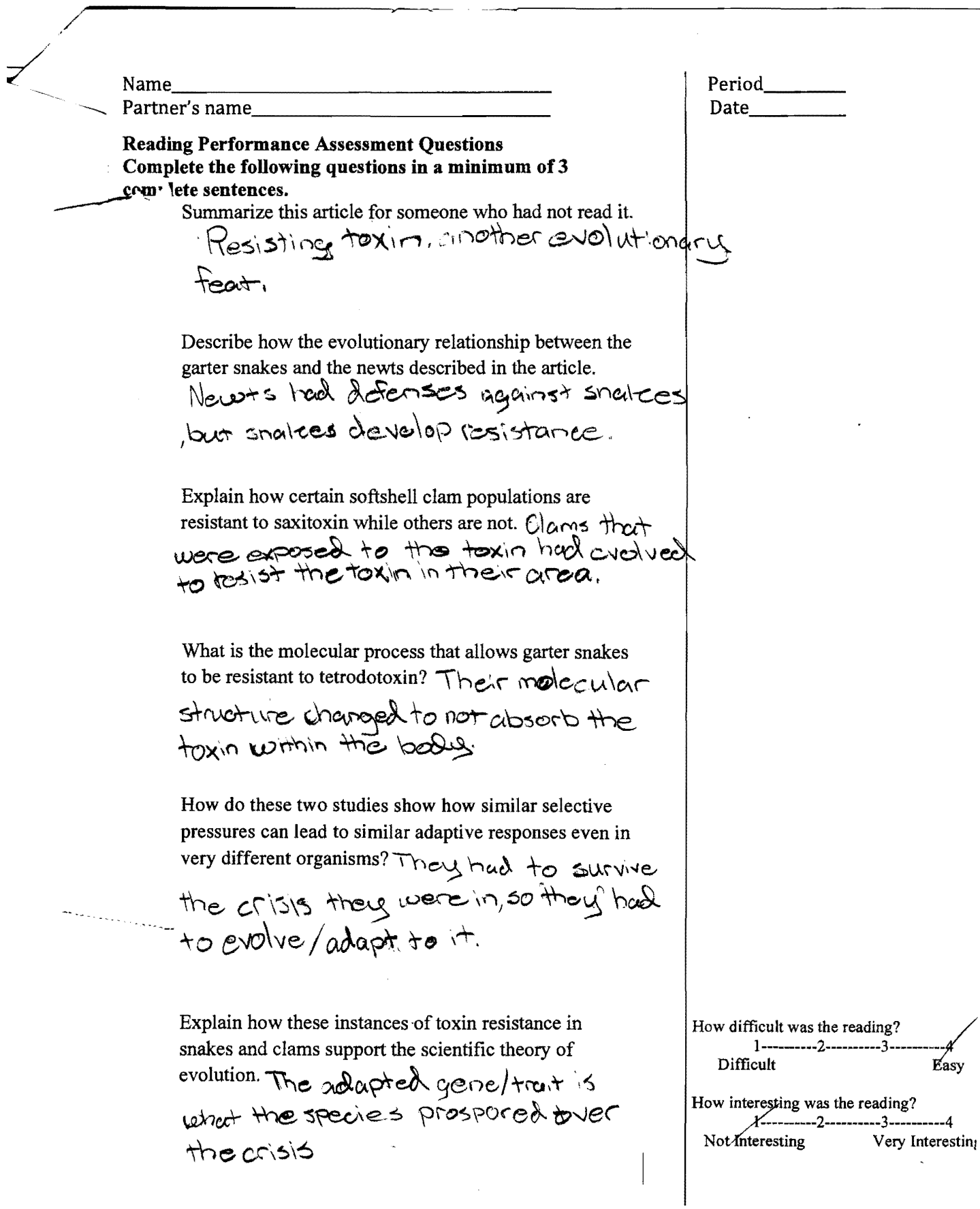


Complete the following questions in a minimum of 3 complete sentences.

1. Summarize this article for someone who had not read it.

Boubosist al discoursing adaptive evolution dy create.

Describe how the evolutionary relationship between the garter snakes and the newts described in the article.

The chokes have adopted resistance fo wald the newts

Explain how certain softshell clam populations are resistant to saxitoxin while others are not.

zee Genetics resist them. lite it sid in the article the clans have it in the tissues.

What is the molecular process that allows garter snakes to be resistant to tetrodotoxin?

Mutation in the cell.

How do these two studies show how similar selective pressures can lead to similar adaptive responses even in very different organisms?

Because the selections ale

- christ Causing similar adp rive SeSpolus.

Explain how these instances of toxin resistance in snakes and clams support the scientific theory of evolution.

they adapt on d evolve

to candice.

How difficult was the reading?

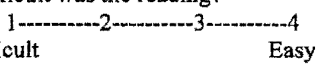

How interesting was the reading?

$1-\cdots-\cdots-.--2$

Very Interesting

98 
Name

Partner's name

Reading Performance Assessment Questions

Complete the following questions in a minimum of 3

complete sentences.

1. Summarize this article for someone who had not read it. The garter snake built a resistance to

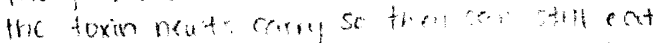
them clams ato bit an ammunty to toxin from red tides.

2. Describe how the evolutionary relationship between the garter snakes and the newts described in the article. The nouts evolved to protect themselves againt srakes, but the qaiter makc evolved and becases communt to the poision from newts.

3. Explain how certain softshell clam populations are resistant to saxitoxin while others are not. Because the algar where the seftchell clons that

are resistant to the roxitoxin creture at tides, so trat at : :one amene

4. What is the molecular process that allows garter snakes it. to be resistant to tetrodotoxin? The |c vel of resistance of garter snakes to the newts can be traced to molecular change that affect the binding of tetrudefoun to a paticular scdium channel.

5. How do these two studies show how similar selective pressures can lead to similar adaptive responses even in very different organisms? If a spece is is critund a toxin for long erough, they car and become resiescule to this toxin.

6. Explain how these instances of toxin resistance in snakes and clams support the scientific theory of evolution. At first these species were not resisteint to the toxin, but then the evolved and necame costant $\rightarrow$ the toxin

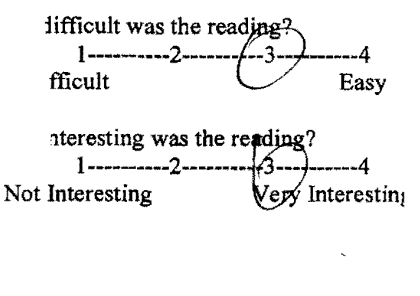




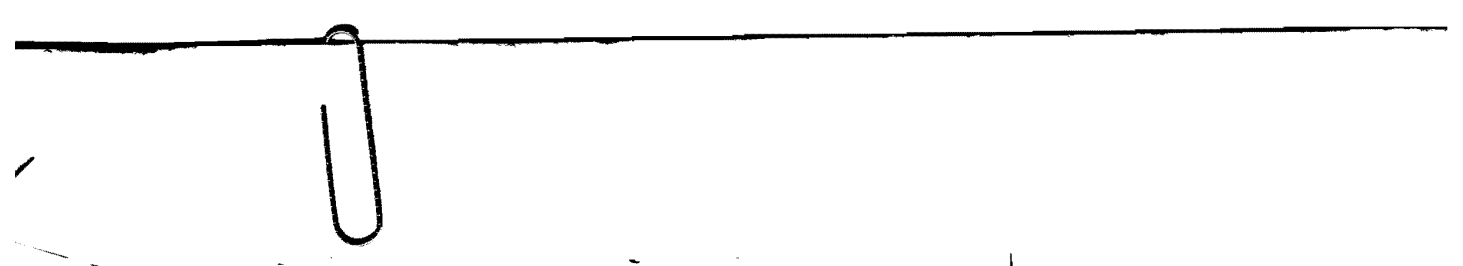

Complete the following questions in a minimum of 3 complete sentences.

1. Summarize this article for someone who had not read it.

Garter snakes evolved to resist toxins.

- Describe how the evolutionary relationship between the garter snakes and the newts described in the article. Both have become resistant to

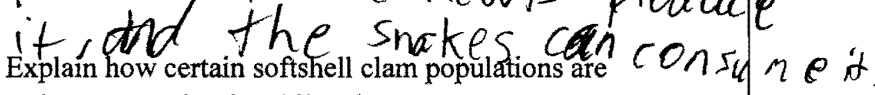
resistant to saxitoxin while others are not.

The ones that consume it a lot are

$$
\text { resistant, ones that don't aren't resistant. }
$$

What is the molecular process that allows garter snakes to be resistant to tetrodotoxin?

a mutation in the gene that looks
at sodium.
. How do these two studies show how similar selective
pressures can lead to similar adaptive responses even in
very different organisms?
If they' re faced with similar
struggles, the ir populations will
be we wed out similarly, producing

similar outcomes.

Explain how these instances of toxin resistance in snakes and clams support the scientific theory of evolution.

Different varieties were present, and were weeded

How difficult was the reading?

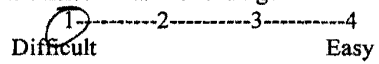

How interesting was the reading?

Interesting

Very Interesting!

100 
molecurize this article for someone who had not read it.

crecite toxing changes cause animals to

They act as or build a resistonce.

genetic adaption.

Describe how the evolutionary relationship between the

The newts evolued described in the article.

their skin as alved tefrodotox in in

snakes evowed defense, but the

snakes evolved to resist the toxin.

Explain how certain softshell clam populations are

resistant to saxitoxin while others are not.

Softshell clams that live in sed tides

generatea by algae resist the toxin

it in the they live in it, and even store

What is the mol tissues.

to be resistant to that allows garter snakes

to besistant to tetrodotoxin?

the molecular Changes affect the

a porticular sodich the Doison) to

doesn't affect them. chonnel, so it

How do these two studies them.

pressures can lead to similar adap how similar selective

very different organisms?

It shows

to have porson animals can aclapt

poison in onder or to resist

a predator, or onder to survive agoinst

a predator, or outside force.

Explain how these instances of toxin resistance in

snakes and clams support the scientific theory of
evolution.

This supports the theory of

evolution in that organism 's

Molecular structures changed

(evolved) to help then

more sucessful a goinst

or their enviroment.

be

predators

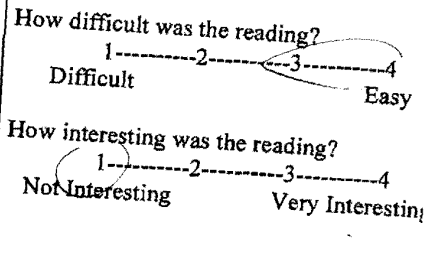


Name

Partner's name

Reading Performance Assessment Questions

Cumplete the following questions in a minimum of 3

\section{lete sentences.}

Summarize this article for someone who had not read it. Jor $i$ some animas have mutated and have weloped resistances to poisons ib jor anmats have.

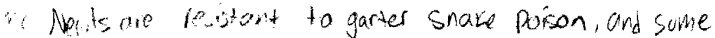
ims are resistant to saxitoxin.

Describe the evolutionary relationship between the garter snakes and the newts described in the article.

The snake, now have more troube eating neuts, elimiraling them as o main food soutce. The snakes ite the neirts $\rightarrow$ tho newts sanget the snares cant cai the newis.

Explain how certain softshell clam populations are resistant to saxitoxin while others are not.

Because the sont'ux resinge gre in popations Which are actually effected saxitoxin some soft sher clams don live in the oreas.

What is the molecular process that allows garter snakes to be resistant to tetrodotoxin?

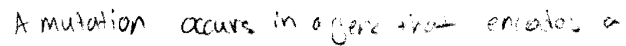
sodium channel at a site aready impicased in the binding of saxituxin.

How do these two studies show how similar selective pressures can lead to similar adaptive responses even in very different organisms?

Berange both rewary of the clams nat Rientive

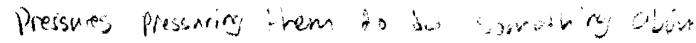
the poisons their predator have ard both colved the problem by developing immunities.

Explain how these instances of toxin resistance in snakes and clams support the scientific theory of evolution.

The two species were presuntio $\rightarrow$ rarge/ mutate, ons it eventually hailierd. Mutations

landomiy ocevas, ord they bon. "re poblens, helping populations eucie a chinc in ine.
Period

Date
How difficult was the reading?

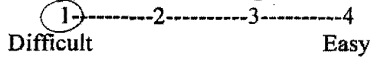

How interesting was the reading?

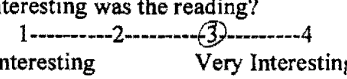




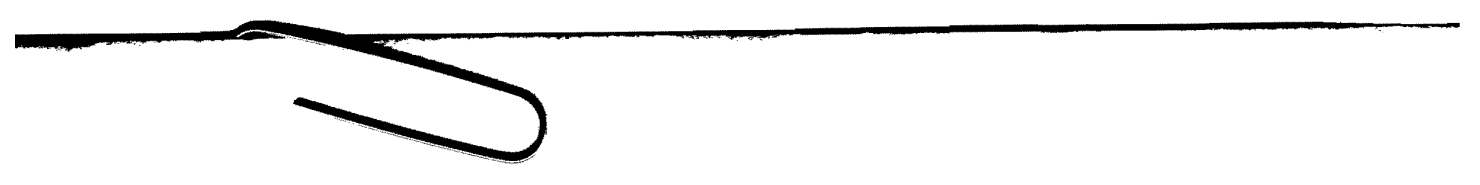

Complete the following questions in a minimum of 3 complete sentences.

- Summarize this article for someone who had not read it. Molecular mechanisms in populations promt aclaptive evaluticrary change. same species that live in different envirchments (different predatcrs) have developed resistances to ald their survival.

2. Describe how the evolutionary relationship between the garter snakes and the newts described in the article. Garter srakes prey on newts. Garter snakes have developed a resistance to the polson tetrodotoxin that neuts produce in defense.

- Explain how certain softshell clam populations are resistant to saxitoxin while others are not. some softshell clams llve in aveas where algae produce red tides (saxitoxin) and some donlt. They had to learn to survive in areas where the alcae was their only food.

1. What is the molecular process that allows garter snakes to be resistant to tetrodotoxin?

Molecular chancies due to a genetic mutation that encode a sodium channel where tetrodotcxin would bind.

5. How do these two studies show how similar selective pressures can lead to similar adaptive responses even in very different organisms?

They both had the same selective pressure. poison in their food sauke.

They needed to develop a resistance in creler to survive and the resistance was through genetic mutations.

6. Explain how these instances of toxin resistance in snakes and clams support the scientific theory of evolution.

Their selective pressure was a poison in their source of food and they needed to develcp a resistance in order to survive. They developed a trait (well, a mutation! which served as a favcrable extrevic which allowed the survival and reproduction of those uro had the mutation.

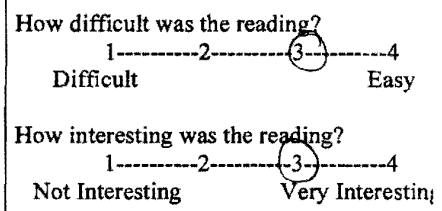




\section{iii. Student responses from final survey questions}

1. When you are reading informational text, how often do you pause to check for understanding? I pavse most of the time ulien 1 dont inderstand a asd or the sentence

a. When you do pause and check for understanding, how does it help you? It helps me think about the cuord and de critical ninking

b. Has the frequency changed since using the think aloud protocol? No

2. How often do you pause on unfamiliar vocabulary and try to predict the meaning of a word or look for clues of the meaning in the text?

1 pause frequently since 1 cant stand

hot understanding a uord.

a. Has the frequency changed since using the think aloud protocol?

No

3. How often do you think about the connection between the information in the text to something you have studied or experienced in the past?

Not frequently. If someting strikes to

a. Has the frequency changed since using the think aloud protocol?

An

4. How does it change your understanding of how to read text when a teacher demonstrates a technique like the think aloud?

4 reminds we that i need to do More

critical thinking and understand pentences

5. Did you find the text difficult? Did you find the text interesting?

a. How does that change the way that you read informational text?

the text was not difficdt. Hlinagn, the

reading was inly intesestag and vid 
1. When you are reading informational text, how often do you pause to check for understanding?

a. When you do pause and check for understanding, how does it help you?

I pause to check for understanding very fiequently and it helps me a lot. Every time I don't understand

b. Has the frequency changed since using the think aloud protocol?

Yes it has. I ured to never stop and

I would finish without any undertanding.

2. How often do you pause on unfamiliar vocabulary and try to predict the meaning. of a word or look for clues of the meaning in the text?

I pause en all unets that are

unfamiliar.

a. Has the frequency changed since using the think aloud protocol?

Yes, because it helps mu understanding.

3. How often do you think about the connection between the information in the text to something you have studied or experienced in the past?

$$
\text { I do not do this. }
$$

a. Has the frequency changed since using the think aloud protocol?

This has not changed.

4. How does it change your understanding of how to read text when a teacher demonstrates a technique like the think aloud? It helps you

think better and harder. It also helps you get on iniage in your head

5. Did you find the text difficult? Did you find the text interesting?

a. How does that change the way that you read informational text?

It was soit of difficult. Some of the

words were challenging. The text was

very interesting! 
1. When you are reading informational text, how often do you pause to check for understanding? all of the time.

a. When you do pause and check for understanding, how does it help you?

$$
\text { whit lim reading better. }
$$

b. Has the frequency changed since using the think aloud protocol?

$$
\text { Notreally }
$$

2. How often do you pause on unfamiliar vocabulary and try to predict the meaning of a word or look for clues of the meaning in the text? all of the tinc

$$
\text { whin f'm randing. }
$$

a. Has the frequency changed since using the think aloud protocol?

$$
\text { Not reme }
$$

3. How often do you think about the connection between the information in the text to something you have studied or experienced in the past? all of f he

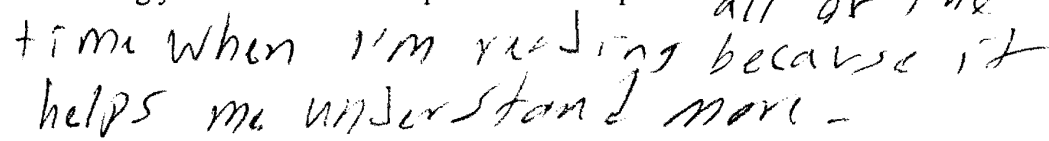

a. Has the frequency changed since using the think aloud protocol?

$$
\text { Not } r a t / \%
$$

4. How does it change your understanding of how to read text when a teacher

$$
\begin{aligned}
& \text { nnderstond of. t t mabes you }
\end{aligned}
$$

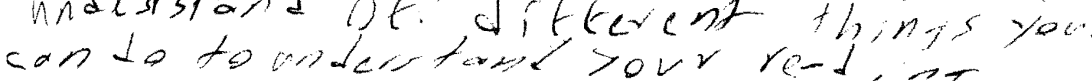

5. Did you find the text difficult? Did you find the text interesting?

a. How does that change the way that you read informational text?

$$
\text { The text las chent? }
$$


1. When you are reading informational text, how often do you pause to check for understanding?

\section{idea what larr coading.}

a. When you do pause and check for understanding, how does it help you?

It is actually rally helpou. It helps me clanty and answer any questions I had aboul the reading.

b. Has the frequency changed since using the think aloud protocol? It has! I end to read things sutloud (whenim

alue) when 1 dunt undertord simetning and it has beer revful snce 1 parely stip niw

2. How often do you pause on unfamiliar vocabulary and try to predict the meaning of a word or look for clues of the meaning in the text?

Not tow often since I tena to catch on quickly.

a. Has the frequency changed since using the think aloud protocol?

No. but tinat's because I rarely stoppd before

3. How often do you think about the connection between the information in the text to something you have studied or experienced in the past?
Alot. It helps me better uraestand what
1 am readirg.

7 a. Has the frequency changed since using the think aloud protocol?
Nop, becaute of the fac that 1 alroady
do.

4. How does it change your understanding of how to read text when a teacher demonstrates a technique like the think aloud?

N it improves $1 t .1$ do it much mure than I

uled toiso H's he'ged.

5. Did you find the text difficult? Did you find the text interesting?

a. How does that change the way that you read informational text?

if its baring. it takes me a little lunges

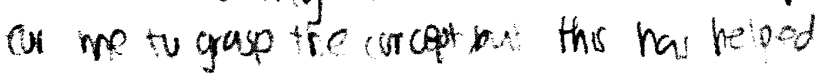


1. When you are reading informational text, how often do you pause to check for

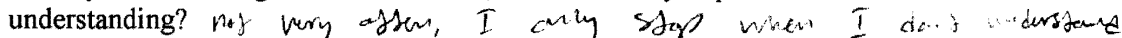

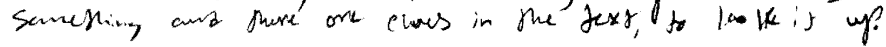

a. When you do pause and check for understanding, how does it help you? Af the and of the text, it heyps becuse I can

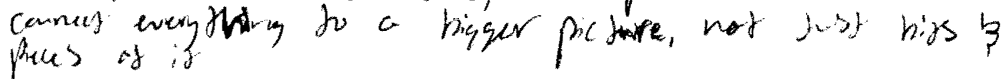

b. Has the frequency changed since using the think aloud protocol? $2 \times 8$.

$$
\text { no, the thinge arad dechnique is onty disoracting to the }
$$

2. How often do you pause on unfamiliar vocabulary and try to predict the meaning of a word or look for clues of the meaning in the text?

nhenever I See on unbanicior word.

a. Has the frequency changed since using the think aloud protocol?

$$
\text { yes, I fend to nor do this when spleaking aland }
$$

3. How often do you think about the connection between the information in the text to something you have studied or experienced in the past?

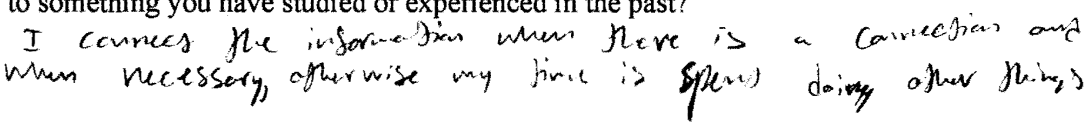

a. Has the frequency changed since using the think aloud protocol? no, if hasiry.

)

4. How does it change your understanding of how to read text when a teacher demonstrates a technique like the think aloud?

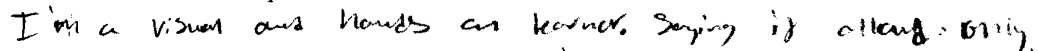

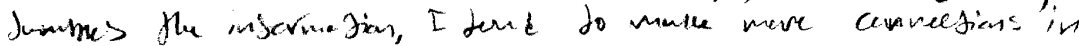
ling heac then ars kend

5. Did you find the text difficult? Did you find the text interesting?

a. How does that change the way that you read informational text?

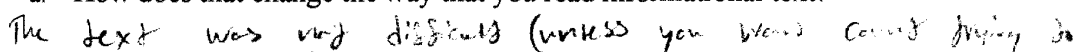

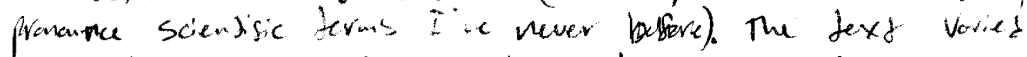

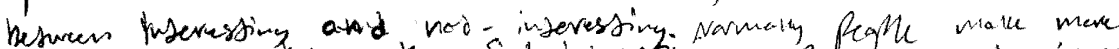

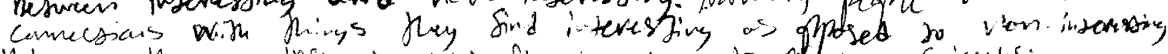

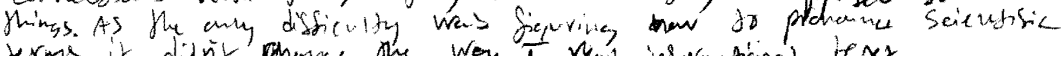


1. When you are reading informational text, how often do you pause to check for understanding?

$$
\text { all the time }
$$

a. When you do pause and check for understanding, how does it help you?

$$
\text { I'll re read to uncherstand the sentence }
$$

b. Has the frequency changed since using the think aloud protocol?

$$
\text { NC }
$$

2. How often do you pause on unfamiliar vocabulary and try to predict the meaning of a word or look for clues of the meaning in the text?

$$
\text { Ido it wl out knowing I doit. }
$$

a. Has the frequency changed since using the think aloud protocol?

$$
\text { Nopers }
$$

3. How often do you think about the connection between the information in the text to something you have studied or experienced in the past?

I don't think about it all the time but when

$$
\text { I do I start relating everuthing... a chain }
$$

a. Has the frequency changed since using the think aloud protocol? reaction of I've started to think about

related things now.

4. How does it change your understanding of how to read text when a teacher demonstrates a technique like the think aloud?

It mabes me think about all the possibilities

the into may relate too.

5. Did you find the text difficult? Did you find the text interesting?

a. How does that change the way that you read informational text?

The texts we read aren't ditlicult but some rocab I don't whav, when I don't know the rocab then its hard for me to concentrait. 
Name

Date

1. When you are reading informational text, how often do you pause to check for understanding?

Never

a. When you do pause and check for understanding, how does it help you?

It makes for better understanding

b. Has the frequency changed since using the think aloud protocol?

No

2. How often do you pause on unfamiliar vocabulary and try to predict the meaning of a word or look for clues of the meaning in the text?

$$
\text { Some times }
$$

a. Has the frequency changed since using the think aloud protocol?

$$
\text { Na }
$$

3. How often do you think about the connection between the information in the text to something you have studied or experienced in the past?

$$
\text { Nevir }
$$

a. Has the frequency changed since using the think aloud protocol?

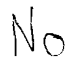

4. How does it change your understanding of how to read text when a teacher demonstrates a technique like the think aloud?

$$
\text { It waker, it so I undretand Petter. }
$$

5. Did you find the text difficult? Did you find the text interesting?

a. How does that change the way that you read informational text?

$$
\begin{aligned}
& \text { It wasn't difficult and it unes kind of interesting } \\
& \text { and this kotes it ersieg to rand }
\end{aligned}
$$




\section{Appendix C: Research Approval Documents}

\section{i. Informed consent for student participation in the study.}

Dear Parent or Guardian,

Your child is invited to participate in a research study conducted by Lindsey Mockel from Portland State University, Center for Science Education. The purpose of this study is to learn if student learning will be improved by integrating literacy strategies in a science classroom. This study is being conducted in partial fulfillment of the requirements for a Masters in Science Teaching under the supervision of Dr. Liza Finkel, Associate Dean for the Graduate School of Education. Your child was selected as a possible participant in this study because (s)he is enrolled in Mrs. Cooper's BCP-10 class where Ms. Mockel is student teaching.

This informed consent will allow Ms. Mockel to use your child's responses to short reading activities as part of the study. These reading activities will take place during the Genetics unit of BCP-10. These reading activities are designed to build literacy skills. Each student will answer several questions after the end of each reading activity. Ms. Mockel may use these responses in the research study. Student names and identification information will be confidential. If you decide that your child will not participate in the study, (s)he will be expected to participate in the activities during the unit of instruction.

Your child may not receive any direct benefit from taking part in this study, but the study may help to increase knowledge about how using literacy strategies can be used to teach science. Any information that is obtained in connection with this study and that can be linked to your child or identify your child will be kept confidential. A code will be assigned to your child's work instead of using his or her name. Only the Mrs. Cooper and Ms. Mockel will review student work. Student information will not be shared with anyone else.

Your child's participation is voluntary. Your child does not have to take part in this study, and his or her participation will not affect your child's grade in the course or relationship with Ms. Mockel. If you have questions about your child's participation in 
this study or questions about the study itself, contact Ms. Mockel at Lindsey_Mockel@beaverton.k12.or.us or (919)-259-0844.

Your signature indicates that you have read and understand the above information and agree that your child may take part in this study. Please understand that you may withdraw your consent at any time without penalty, and that, by signing, you are not waiving any legal claims, rights or remedies. If requested, the Ms. Mockel will provide you with a copy of this form for your own records and/or a summary of the research results.

\begin{tabular}{lll}
\hline Student's name (Please print.) & Student's signature & Date
\end{tabular}

Parent/Guardian's name (Please print.) $\quad$ Parent/Guardian's Signature Date 
ii. Final Application for Human Subjects.

I. Investigator's Assurance (to be attached)

\section{Project Title \& Prospectus}

This study, Thinking-Aloud: Can a literacy strategy increase student achievement in science?, will investigate if integrating a literacy strategy into high school science curriculum will improve student achievement. Think-aloud is a literacy strategy used and recommended by literacy coaches to improve reading comprehension. The proposed study will investigate if integrating think-aloud into a science curriculum will improve student achievement in science. High school students enrolled in BCP-10, an integrated biology, chemistry and physics course for sophomores, will participate in the study. As part of the study, students will participate in think-aloud routinely during class activities. The researcher will ask students to complete the Science Reading Work Sample as a pretest and as a post-test. The work sample asks students to read a selected text and answer six questions. Student achievement will be defined as their ability to answer the selected questions. Several BCP-10 class sections in the same science curriculum will be chosen for the study. These BCP-10 class sections will experience the literacy strategy as part of their instruction; at least one section will be delayed in participating in the literacy strategy and will therefore act as a control group. The researcher will interview eight participants in the presence of the master teacher. This proposed study expects to find that student achievement will improve as a result of integrating think-aloud in science curriculum.

\section{Exemption Claim for Waiver of Review}

I am not asking for a waiver of review. 


\section{Subject Recruitment}

High school students at Beaverton High School in the Beaverton School District will be participants in this study. Students will be selected to participate in the study based on their enrollment in BCP-10 class section where the researcher is assigned as a student teacher. Classroom size may range from 28-34 students. It is expected that between $60-80 \%$ of students in each section will provide informed consent. BCP-10 is a year long, required science course for all students in $10^{\text {th }}$ grade. Therefore the age range of students may be from 16-17 years old. Beaverton School District enrolled 38,571 students in the 2010-2011 school year. Forty-six percent of students identified themselves as a minority ethnicity. Twelve percent of students enrolled as Special Education Students. Fourteen percent of students enrolled as English as a Second Language student. Thirty-eight percent of students qualified for Free and Reduced Lunch, and eleven percent of students enrolled as Talented and Gifted. It is expected that a similar student demographic will participate in this study.

\section{Informed Consent}

Before information is gathered for the purposes of the study, the researcher will obtain informed consent from each participant. The researcher will be assigned as a student teacher in five sections of BCP-10. Students enrolled in these sections will be potential participants in the study. A letter to explain the study will be sent to the parent or guardian of each student. Each parent or guardian will also receive a document of informed consent. After receiving informed consent documentation from their parent or guardian, the researcher will assign students as participants in the study. All students in the BCP-10 course sections will participate in the literacy strategies and Science Reading 
Work Sample as part of their instruction. The scores on the Science Reading Work Sample by participants in the study will be used confidentially as data. The scores on the Science Reading Work Sample from students who do not provide informed consent will not be used as data for the study. Confidentiality will be protected for all students.

\section{First Person Scenario}

For the group of students who will use think-aloud throughout the four-week instructional unit on Genetics:

I am a high school sophomore enrolled in Mrs. Cooper's BCP-10 class. This year Mrs. Cooper has a student teacher, Ms. Mockel, working with her. Ms. Mockel is going to teach the next unit of instruction on Genetics. She has informed the class that she will be doing research while she teaches the unit of instruction. She described the research to us during class. She also gave each of us two documents to take home to our parents. I took the letter describing the research home to my parents. I also gave them the document for informed consent. After reading the letter and the informed consent document, my parents signed it. I returned the signed informed consent to Ms. Mockel the next day. A few weeks later, Ms. Mockel began her unit of instruction on Genetics. On the first day, she asked us to do was to sit in pairs and read aloud a selection of scientific text. I sat with my partner, and we took turns reading the text aloud. Then we each answered six questions about the text individually. Everyone in the class participated, and we all turned our paper into Ms. Mockel. Ms. Mockel then told us that we are going to use think-aloud during class. She modeled the think-aloud to the whole class as she read text about Genetics. Over the next few class periods, we practiced using the think-aloud while reading text about Genetics. Two weeks into the unit on Genetics, Ms. Mockel asked us 
to practice the think-aloud and answer the six questions again. We all submitted our papers to Ms. Mockel. We practiced the think-aloud several more times during class. At the end of the unit, Ms. Mockel asked us to practice the think-aloud one more time and answer the six questions again. We all submitted our papers to Ms. Mockel. For the group of students who will use think-aloud only during the second half of the four week unit on Genetics:

I am a high school sophomore enrolled in Mrs. Cooper's BCP-10 class. This year Mrs. Cooper has a student teacher, Ms. Mockel, working with her. Ms. Mockel is going to teach the next unit of instruction on Genetics. Ms. Mockel has informed the class that she will be doing research while she teaches Genetics. She described the research to us during class. She also gave us all two documents to take home to our parents. I took the letter describing the research home to my parents. I also gave them the document for informed consent. After reading the letter and the informed consent document, my parents signed it. I returned the signed informed consent to Ms. Mockel the next day. A few weeks later, Ms. Mockel began her unit of instruction. The first thing she asked us to do was to sit in pairs and read aloud a selection of scientific text. I sat with my partner, and we took turns reading the text aloud. We each then answered six questions about the text individually. Everyone in the class participated, and we all turned our paper into Ms. Mockel. For two weeks, Ms. Mockel asked us to read aloud scientific text on Genetics with a partner several more times during class. After two weeks, Ms. Mockel asked us to read scientific text aloud with our partners and answer six questions about the text. We all submitted our papers to Ms. Mockel. The next day, Ms. Mockel told us that we are going to use think-aloud when we read text during class. She modeled the think-aloud to the 
whole class as she read scientific text about Genetics. Over the next few class periods, we practiced using the think-aloud while reading text about Genetics. At the end of the fourweek unit, Ms. Mockel asked us to practice the think-aloud one more time with our partner and answer six questions. We all submitted our papers to Ms. Mockel. For the students selected for student interviews:

After I consented to participate in the study, Ms. Mockel asked if I was willing to be interviewed. I met Ms. Mockel in Mrs. Cooper's classroom for a few minutes after school. Mrs. Cooper was also in the classroom, but Ms. Mockel conducted the interview. Ms. Mockel asked me several questions. She took notes after I answered each question. The interview lasted about 10 minutes. After the four-week unit of instruction, Ms. Mockel scheduled another interview with me. I met Ms. Mockel in Mrs. Cooper's classroom just like the first interview. She asked me the same questions and took notes. The interview lasted about 10 minutes.

\section{Potential Risks and Safeguards}

Students will be asked to read text aloud and to respond to the text aloud using the think-aloud protocol. In order to reduce discomfort in the practice, the researcher will model the techniques several times for students. In addition, students will be given opportunities to practice the technique without consequence to the study or their grade. The researcher will offer safeguards to the students by providing a classroom culture that nurtures respect, kindness, courtesy and safety. Students will participate in the study as part of daily classroom instruction.

\section{Potential Benefits}


Research in science education shows that integrating literacy strategies in science curriculum can improve student achievement in science and language literacy. Pearson et al. (2010) reviewed studies that investigated the role between science inquiry and literacy-based strategies in educational curriculum. The authors chose studies that integrate literacy-based pedagogical practices in science content classrooms. Pearson et al. (2010) cited research that integrates language literacy strategies into science education. These studies show an increase in student achievement in both science and language literacy. Although the authors recognized the difficulties that hinder the integration of science curriculum and language literacy, they emphasized the necessity of explicit instruction in literacy skills as students read scientific text. The authors called for research to extend the current body of literature and to identify the most effective aspects of these literacy-based interventions.

In addition, Hapgood and Palincsar (2007) synthesized a body of research that highlights the use of language literacy strategies when students read scientific text. In their synthesis, the authors discussed opportunities for integrating scientific inquiry with reading, writing and oral language literacy strategies. The authors suggested implications for pedagogical practice to include explicit instruction in literacy strategies as students learn to read scientific texts.

In support of the impact of language literacy and science education, Norris and Phillips (2003) highlighted the significance of pedagogical practices that teach critical reading skills in content areas. As the authors acknowledged the importance of decoding science text, they described an ideal level of reading comprehension as the ability to 
interpret any scientific text. This description of science content literacy exemplifies the importance of language literacy skills as students read and comprehend scientific text.

Yore et al. (2004) also described the importance of the integrating language literacy skills in science education in order to improve student learning in science. The authors emphasized that comprehension, discussion and writing argument are language literacy skills necessary for achievement in science content. The authors described reading comprehension as necessary to derive meaning from scientific text. The authors called for research into the cognitive processes used by those who expertly read and comprehend scientific text to inform pedagogical practices in science education.

From this research, the researcher has confidence in the potential benefits of the think-aloud protocol on student learning. By integrating this literacy strategy into a unit of instruction on Genetics, I am confident that students will benefit in both their language literacy and science content knowledge. Each student, whether they participate in the research or not, will have an opportunity to practice and improve a valuable literacy skill. Literacy skills benefit students in every academic content area.

Hapgood, S. \& Palincsar, A.S. (2007). Where Literacy and Science Intersect. Educational Leadership, 64(4), 56-60.

Pearson, P. D., Moje, E., Greenleaf, C. (2010). Literacy and Science: Each in the Service of the Other. Science, 328, 459-463.

Norris, S.P., \& Phillips, L.M. (2003). How Literacy in Its Fundamental Sense Is Central to Scientific Literacy. Science Education, 87(2), 224-240.

Yore, L. D., Hand, B., Goldman, S.R., Hildebrand, G.M., Osborne, J.F., Treagust, D.F., \& Wallace, C.S. (2004). New Directions in Language and Science Education Research. Reading Research Quarterly, 39(3), 347-352. 


\section{Confidentiality, Records \& Distribution}

Student names will be coded to conceal student identity both during the course of research and in the period thereafter. Student names will never be used to report data. Individual student information will never be used to report data. In a classroom setting, student confidentiality cannot be guaranteed. The researcher will safeguard data from all participants in the study. Data will be stored on the personal computer of the researcher, and student names will never be recorded with the data. The study will begin in February 2012. Data collection will be obtained over a four-week curriculum unit. The researcher will complete data analysis and defend a thesis in August 2012. After the required three years and the completion of the researcher's thesis defense, all data will be erased from storage. Students will not be audiotaped without consent. No student will be videotaped. 
iii. $\quad$ Portland State University Institutional Review Board Approval Memo.

\section{龟 Portland State}

\section{Portland State University HSRRC Memorandum}

To: Lindsey Mockel

From: Mary Oschwald, Chair, HSRRC 2012

Date: May 29, 2012

Re: Your HSRRC application titled, "Thinking Aloud in the Science classroom" (HSRRC Proposal \#111962)

In accordance with your request, the Human Subjects Research Review Committee has reviewed your proposal referenced above for compliance with DHHS policies and regulations covering the protection of human subjects. The committee is satisfied that your provisions for protecting the rights and welfare of all subjects participating in the research are adequate, and your project is approved.

Please note the following requirements:

Changes to Protocol: Any changes in the proposed study, whether to procedures, survey instruments, consent forms or cover letters, must be outlined and submitted to the Chair of the HSRRC immediately. The proposed changes cannot be implemented before they have been reviewed and approved by the Committee.

Continuing Review: This approval will expire 05/29/2013, one year from the approval date. It is the investigator's responsibility to ensure that a Continuing Review Report (available in ORSP) of the status of the project is submitted to the HSRRC approximately two months before the expiration date, and that approval of the study is kept current.

Adverse Reactions: If any adverse reactions occur as a result of this study, you are required to notify the Chair of the HSRRC immediately. If the problem is serious, approval may be withdrawn pending an investigation by the Committee.

Completion of Study: Please notify the Chair of the Human Subjects Research Review Committee (campus mail code ORSP) as soon as your research has been completed. Study records, including protocols and signed consent forms for each participant, must be kept by the investigator in a secure location for three years following completion of the study. 
If you have questions or concerns, please contact the HSRRC in the Office of Research and Strategic Partnerships, Market Center Building, Suite 620, 1600 SW Fourth Ave, Portland OR 97207 (503)725-2243.

cc: Ann Stephenson, Liza Finkel 


\section{Appendix D: An Account of a Think Aloud Protocol}

During the first day of the unit on evolution, the researcher modeled the think aloud protocol. The following two sections will describe the coaching and experience of Period 1 and Period 3. The experience of Period 4 will be addressed in following sections. As students entered the classroom, they were instructed to retrieve the formatted text, "Living Ancestors of Whales" (see Appendix A), and sit with a partner. For an odd number of students, one group of three was allowed. Students were not intentionally paired, and a seating chart was not used during the study. Students were not required to sit with the same partner for each activity; they were only required to name their partner on the formatted text. Because all students participated in the reading activities, participants and non-participants may have completed the activity together. All students were expected to participate in the activity and practice the think aloud protocol.

After students retrieved the formatted text and sat with a partner, the researcher

explained and modeled the think aloud protocol. The researcher explained to Period 1 and Period 3 that they would be starting each class during the evolution unit by reading aloud a short article and answering several questions. Students were told that they were expected to follow specific instructions when reading aloud the text. The researcher then demonstrated the think aloud protocol to the students. See Appendix D for a detailed description of how the researcher modeled the think aloud protocol.

The researcher presented the think aloud protocol using an overhead transparency projector. To begin, the formatted text was introduced to the students by the researcher. The instrument includes two sections of instructions, one for the reader and one for the partner. Students were instructed that while each person in the pair would have a specific 
role to begin the activity, there is an embedded instruction that requires the students to switch roles. The role of the reader is to read aloud the informational text. The reader should pause every two or three sentences to think aloud, which may include commenting to show understanding of the text, voicing questions aloud, or voicing connections to prior knowledge or experiences. The reader continues in that role until the embedded prompt, 'switch readers.' The reader then takes the role as listener and does the following. The listener marks the text using the following guidelines: circle new vocabulary, underline main idea, write questions, predictions, or connections $n$ the 2.5inch margin on the right of the formatted text. Both students have a designated role during the activity. Both students have an opportunity to act as reader and listener for each experience with the think aloud protocol. The researcher demonstrated both roles using the overhead transparency projector. 